\title{
O PAPEL EXERCIDO PELO PRONAF EM MUNICÍPIOS DE PEQUENO PORTE NO OESTE PAULISTA
}

\author{
THE ROLE EXERCISED BY PRONAF IN SMALL MUNICIPALITIES IN THE WEST OS SÃO PAULO
}

\author{
Paulo Cesar Souza ${ }^{1}$, Antonio Nivaldo Hespanhol ${ }^{1}$ \\ ${ }^{1}$ Universidade Estadual Paulista "Júlio de Mesquita Filho" (UNESP), Presidente Prudente, SP, Brasil
}

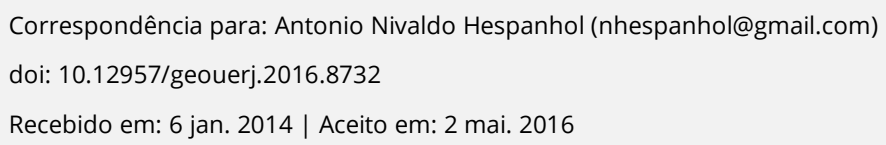

\section{RESUMO}

A partir da década de 1990, com a retomada do processo democrático e a nova constituição nacional, algumas políticas públicas foram sendo implementadas pelo governo federal com vias de beneficiar os produtores rurais, principalmente a classe dos pequenos e médios produtores, hoje conhecidos como agricultura familiar. A mais importante e eficaz delas foi o PRONAF, que visa atender produtores rurais de baixa renda, residentes no meio rural e/ou nos municípios onde possuem a propriedade e que dependem quase que eminentemente da produção agrícola para sustento da família. O PRONAF se propagou pelo território nacional e seus recursos puderam ser captados por produtores de todo o Brasil. Esse texto analisa o papel exercido pelo programa em municípios de pequeno porte situados no Oeste Paulista, e busca compreender a influência desta política pública nas economias locais, bem como seus aspectos positivos no que diz respeito à participação compartilhada do poder público, das associações de produtores e dos proprietários rurais na captação e utilização dos incentivos, com vias de promover o desenvolvimento territorial.

Palavras-chave: Agricultura familiar; Pronaf; Oeste Paulista; Desenvolvimento territorial.

\begin{abstract}
From the early 1990, with the resumption of the democratic process and the new national Constitution (1988), some public policies were being implemented by the Federal Government with ways to benefit the farmers, especially the class of small and medium producers, today known as family agriculture. The most important and effective of these was the $P R O N A F$, that serve low-income rural producers, rural residentsand and/or in the municipalities where they have property and that depend on almost exclusively of the agricultural production for family sustenance. The PRONAF has swept through the national territory and its resources could be obtained by producers of all Brazil. This text examines the role exercised by program in small municipalities situated in the West of São Paulo, and tries to understand the influence of this public policy in local economies, checking if the positive aspects regarding the shared participation of the Government, the associations of producers and Landowners on the uptake and use of incentives, with ways to boost of territorial development.
\end{abstract}

Keywords: Family agriculture; Pronaf; West of São Paulo; Territorial Development

\section{INTRODUÇÃO}

Neste artigo é apresentada parte dos resultados da pesquisa sobre políticas públicas e desenvolvimento rural realizada em municípios do interior paulista ${ }^{1}$. A investigação teve como objetivo principal

\footnotetext{
${ }^{1}$ Pesquisa de Doutorado em Geografia "Políticas Públicas e Desenvolvimento Rural na Região de Presidente Prudente" (2012), FCT/UNESP, Campus de Presidente Prudente. 
analisar o papel do Programa Nacional de Fortalecimento da Agricultura Familiar (PRONAF) em oito municípios da Região de Presidente Prudente - SP.

Na primeira parte do artigo é apresentada a evolução do PRONAF como política pública e, em seguida, a sua importância para os municípios do Oeste Paulista. Na terceira parte são apresentados dados que evidenciam a importância e as repercussões do PRONAF para a economia dos municípios. Nas considerações finais são feitos apontamentos sobre a importância das políticas públicas com foco na agricultura familiar.

\section{O PROGRAMA NACIONAL DO FORTALECIMENTO DA AGRICULTURA FAMILIAR}

A agricultura familiar passou a ser oficialmente reconhecida e a receber tratamento diferenciado pelas políticas públicas somente a partir de meados dos anos 1990. Dentre os estudos que demonstram a importância da agricultura familiar no Brasil, destacam-se: Veiga (1991), Abramovay e Veiga (1999), Graziano da Silva (1998; 1999), Kageyama (2003), Wanderley (2003), Schneider (2003) e, mais recentemente, Favareto (2007; 2010), Bonnal e Maluf (2009), Navarro (2010) e Cazzela (2010).

Em 1995 foi criado o PRONAF que impulsionou os debates sobre a agricultura familiar no Brasil e foi fundamental para o reconhecimento desta categoria de produtores rurais.

Nos anos 1990 os municípios foram incentivados a instituir os seus Conselhos Municipais de Desenvolvimento Rural (CMDRs), os quais receberam a incumbência de elaborar os Planos Municipais de Desenvolvimento Rural (PMDRs)², para terem acesso a linha de crédito do PRONAF denominada "Infra-Estrutura e Serviços Municipais".

Um dos princípios dessa linha de crédito do PRONAF foi propiciar a participação da sociedade nas decisões sobre os incentivos a serem oferecidos às localidades, bem como promover o associativismo

\footnotetext{
${ }^{2}$ Andrade (2004); Hespanhol e Hespanhol (2004).
} 
rural e a participação política dos agricultores familiares ${ }^{3}$. Com a efetivação do PRONAF foi delineado o caminho para uma nova fase do rural brasileiro, mesmo que muito haveria de se discutir posteriormente sobre a heterogeneidade do rural e a diversidade da produção familiar e o seu papel no desenvolvimento local.

\section{A importância do PRONAF como política de desenvolvimento territorial}

Desde sua criação, o PRONAF tem sido uma política pública de concessão de crédito de grande importância para o produtor rural, atendendo, sobretudo, pequenos e médios produtores. Nesse sentido, o programa vem contribuindo para diminuir as disparidades regionais (SCHNEIDER, 2003; 2007; PAULILO, 2004). De acordo com Abramovay e Veiga (1999), a linha de crédito InfraEstrutura e Serviços Municipais foi inovadora e beneficiou os municípios e os pequenos produtores.

Em 1994, como resposta às reivindicações dos movimentos sociais, o Estado buscou viabilizar estabelecer políticas públicas que satisfizessem as categorias menos favorecidas do campo. Primeiramente, o Governo Itamar Franco criou o Programa de Valorização da Pequena Produção Rural (PROVAP), operando com recursos do Banco Nacional do Desenvolvimento Social (BNDES) ${ }^{4}$. O governo FHC reformulou o programa, criando o PRONAF, por meio do Decreto Presidencial 1.946, de 28/06/1996. Esse programa inovador trouxe novas possibilidades para a agricultura familiar duramente assolada pela crise do Estado, pelo fim dos subsídios concedidos por intermédio do Sistema Nacional de Crédito Rural (SNCR) e o endividamento dos produtores ${ }^{5}$.

Em 2003, foram ampliadas as fontes de recursos do PRONAF. Além do Fundo de Assistência ao Trabalhador (FAT), passaram a ser utilizados os Fundos Constitucionais do Nordeste (FNE) e do

\footnotetext{
${ }^{3}$ Segundo Andrade (2009, p. 238), os conselhos municipais estavam ligados diretamente ao PRONAF, poderiam representar um "[...] papel protagônico no desenvolvimento local" e funcionariam com a "[...] parceria do poder público com entidades representativas" da sociedade.

${ }^{4}$ Marco de referência nas mudanças das diretrizes institucionais da agricultura brasileira (SCHNEIDER; CAZZELA; MATTEI, 2004).

${ }^{5}$ Para Silva e Marques (2004), o PRONAF obteve o "selo de prioridade" dentro do Programa "Comunidade Solidária", um dos poucos de viés eminentemente social do Governo Federal, na década de 1990.
} 
Centro-Oeste (FCO) e dos Bancos Cooperativos ${ }^{6}$ (SCHNEIDER; CAZELLA; MATTEI, 2004). Aos poucos o programa se tornou conhecido no âmbito da agricultura familiar e suas linhas de crédito foram se tornando adequadas aos diversos perfis de produtores (VEIGA; ABRAMOVAY, 1999). As linhas de crédito mais conhecidas são: a) PRONAF Crédito; b) PRONAF Investimentos; c) PRONAF Agroecologia; d) PRONAF(s) Mulher e Jovem; e) PRONAF para os municípios (MDA/SAF, 2009) ${ }^{7}$.

O objetivo geral do PRONAF é "[...] fortalecer a capacidade produtiva da agricultura familiar; contribuir para a geração de emprego e renda nas áreas rurais e melhorar a qualidade de vida dos agricultores familiares".

O PRONAF possui quatro objetivos específicos:

a) Ajustar as políticas públicas de acordo com a realidade dos agricultores familiares; b) viabilizar a infra-estrutura necessária à melhoria do desempenho produtivo dos agricultores familiares; c) elevar o nível de profissionalização dos agricultores familiares através do acesso aos novos padrões de tecnologia e de gestão social; d) estimular o acesso desses agricultores aos mercados de insumos e produtos (SCHNEIDER; CAZELLA; MATTEI, 2004, p. 24).

Do ponto de vista operacional, suas linhas de atuação são quatro: a) financiamento da produção: custeio e investimento; b) financiamento de infraestrutura e serviços municipais; c) capacitação e profissionalização dos agricultores; d) financiamento de pesquisa e extensão rural (SCHNEIDER; CAZELLA; MATTEI, 2004).

Por intermédio do estudo realizado pela FAO/INCRA (1994) foi estabelecido o referencial necessário para classificar os estabelecimentos familiares no país (SCHNEIDER; CAZELLA; MATTEI, 2004; FAVARETO, 2007).

\footnotetext{
${ }^{6}$ Esses fundos, criados na Constituição de 1988, favoreceriam o desenvolvimento das regiões mais pobres, com verbas do Tesouro Nacional e do Orçamento da União. Em 1995, o Conselho Monetário Nacional autorizou a criação de bancos de crédito cooperativos de caráter privado, que pudessem atuar nessa área (SCHNEIDER; CAZELLA; MATTEI, 2004).

${ }^{7}$ Existem também modalidades especiais de crédito, como: a) custeio para Agroindústrias Familiares; b) para integração de cotas das Cooperativas de Crédito-Rural; c) PRONAF Agroindústria; d) PRONAF florestas; e) PRONAF Semiárido; f) PRONAF Mulher; g) PRONAF Jovens e outras linhas (SOUZA e VALENTE Jr., 2004).
} 
Foram definidos os seguintes critérios para o enquadramento na categoria de agricultor familiar: a) agricultores com pelo menos $80 \%$ da renda familiar proveniente das atividades agropecuárias; b) explorar estabelecimentos agropecuários com área de até quadro módulos (agricultura) e até seis (pecuária); c) ser proprietário da terra, meeiro, parceiro ou arrendatário; d) utilizar mão-de-obra essencialmente familiar, com até dois empregados; e) morar no imóvel, bairro rural ou vila, ou aglomerado urbano mais próximo; f) possuir renda bruta familiar de até $\mathrm{R} \$ 100.000,00$. (MDA/SAF, 2010; SCHNEIDER; CAZELLA; MATTEI, 2004).

De modo geral, o programa apresentou crescimento expressivo desde a sua criação e tem sido importante para a agricultura familiar e o desenvolvimento rural. No figura 1 verifica-se a evolução do número de contratos e volume de recursos despendido no programa entre 1995 e 2005, destacando-se a grande ampliação do volume de recursos aplicados a partir de 2003 , primeiro ano de mandato do governo Lula.

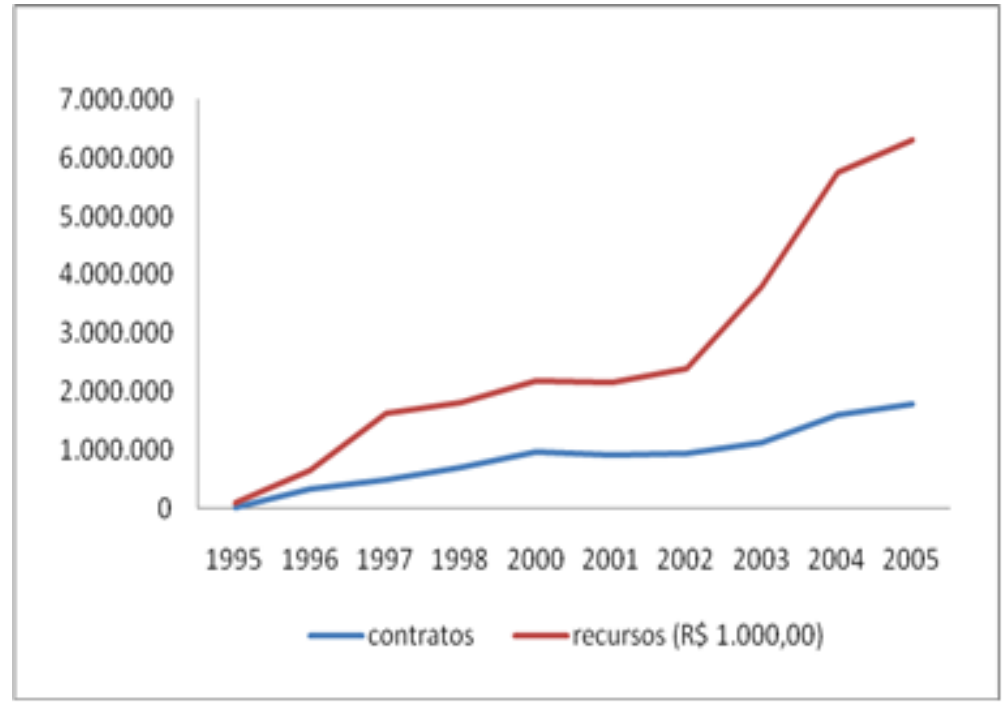

Figura 1. Evolução do PRONAF no Brasil (1995 - 2005): número de contratos e recursos (R\$).

Fonte: Reproduzido com base em Schneider, Cazella e Mattei (2004) e Contratos e Montante; Mattei (2006) apud Guanziroli (2007); MDA/SAF. Org. Paulo Cesar de Souza.

No decorrer dos dez primeiros anos de sua vigência o programa atingiu todo o território nacional (MDA/SAF, 2010). Nesse período ressaltaram-se os seguintes aspectos: a) a concentração dos recursos nas Regiões Sul, Nordeste e Sudeste; b) o número de contratos foi maior nas Regiões Sul e Nordeste; c) os grupos que mais se beneficiaram foram os com renda anual de até $\mathrm{R} \$ 11.000,00$ 
(GUANZIROLI, 2007; ABRAMOVAY e VEIGA, 1997). Para Bonal e Maluf (2007) não restam dúvidas de que se trata de uma política pública estabelecida como divisor de águas para a agricultura brasileira, mesmo porque

(...) o PRONAF constitui o primeiro e mais importante exemplo de política setorial diferenciada dirigida para a agricultura e o mundo rural no Brasil, mais precisamente, uma política diferenciada segundo um recorte social que define uma categoria de agricultor a qual se associa um tipo de agricultura. Uma segunda característica importante do programa foi ter introduzido, nesse domínio, a perspectiva de formulação e implementação de políticas públicas com participação social na forma de conselhos nas três esferas de Governo. (BONAL; MALUF, 2007, p. 14).

A instituição do PRONAF resultou no crescimento da oferta de crédito e incentivos à agricultura familiar, no incremento da participação dos produtores familiares nos programas locais e na diversificação de pesquisas referentes ao desenvolvimento territorial ${ }^{8}$. No caso brasileiro, um dos desafios era e continua sendo o de contemplar a heterogeneidade espacial, social e cultural das diversas categorias de pessoas ligadas à produção agropecuária e a imensa diversidade regional.

Nas diversas regiões do Brasil a agricultura familiar, ainda que enfraquecida e descapitalizada, fez parte da construção do espaço geográfico, da configuração social do território e da dinâmica produtiva e econômica. Na Região de Presidente Prudente, desde os primórdios da colonização, os agricultores familiares têm participado ativamente da geração de riqueza.

\section{O PERFIL DA PRODUÇÃO FAMILIAR E O PRONAF EM MUNICÍPIOS PESQUISADOS NA REGIÃO DE PRESIDENTE PRUDENTE}

Para melhor compreender as realidades locais e as condições socioeconômicas da agricultura familiar na Região de Presidente Prudente foram analisados dados referentes ao PRONAF em oito municípios que possuem as suas bases econômicas ligadas a produção agropecuária e que se situam nas

\footnotetext{
${ }^{8}$ Definições, análises e estudos sobre a evolução e a eficiência do PRONAF, estão presentes em vários trabalhos, com destaque para os de Abramovay e Veiga (1999), R. Hespanhol (2000), Schneider, Cazella e Mattei (2004), Kageyama (2003), Guanziroli (2007) e Bonnal e Maluf (2007; 2009).
} 
proximidades da cidade de Presidente Prudente, quais sejam: Alfredo Marcondes, Álvares Machado, Caiabu, Emilianópolis, Indiana, Martinópolis, Presidente Bernardes e Santo Expedito.

Desde a década de 1990, muitos pequenos e médios produtores rurais da região têm utilizado recursos do PRONAF para custear as lavouras, a exploração leiteira e a criação de aves e pequenos animais, bem como para realizar investimentos em máquinas, implementos e infraestrutura nas propriedades rurais.

A experiência com o PRONAF tem modificado, aos poucos, as opiniões dos produtores a respeito dos incentivos públicos para o setor agropecuário, mesmo porque, entre 1980 e 1995, muitos agricultores enfrentaram problemas com financiamentos bancários. Dentre os 80 produtores rurais pesquisados, 27 tiveram acesso ao PRONAF entre os anos de 1999 e 2010.

No figura 2 verifica-se que, entre os anos agrícolas 1999/2000 e 2008/2009, o maior montante de recursos do PRONAF foi destinado aos municípios de Presidente Bernardes, $(\mathrm{R} \$ 8.926 .721,14)$, Martinópolis, $(\mathrm{R} \$ 6.374 .659,64)$ e Álvares Machado, com $(\mathrm{R} \$ 4.596 .692,47)$, considerando-se os oito municípios investigados.

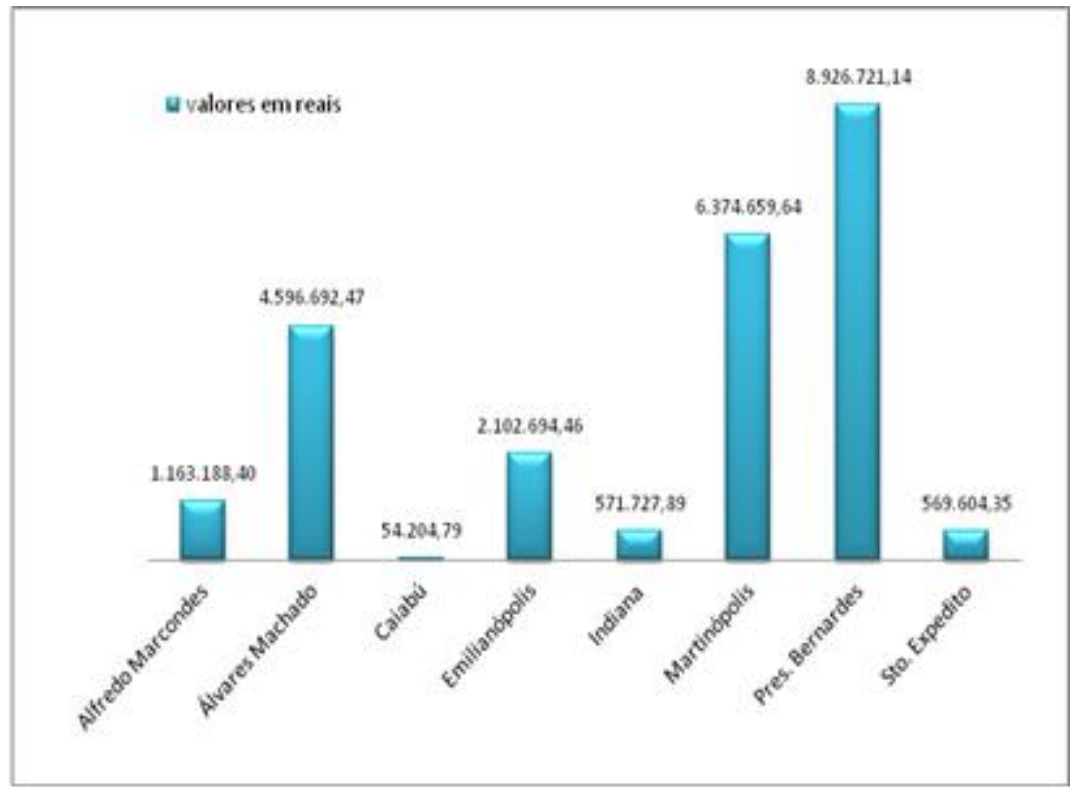

Figura 2. Montante de recursos do PRONAF utilizado pelos produtores rurais nos oito municípios pesquisados no EDR de Presidente Prudente/SP - série histórica 1999/2000 a 2008/2009.

Fonte: www.mda.gov.br/saf, $1^{0}$ sem 2010. 
Nas figuras 3, 4 e 5 são apresentadas as evoluções dos montantes de créditos nos municípios que mais receberam recursos do PRONAF entre os anos agrícolas de 1999/2000 e 2008/2009. Em Presidente Bernardes e Martinópolis, houve aumento do volume de recursos do PRONAF a partir dos anos agrícolas de 2001/02 e 2003/2004, oscilando negativamente entre os anos agrícolas 2006/2007 e $2007 / 2008$.

Nestes, a evolução do montante se deu no período de implantação de assentamentos dos "trabalhadores rurais sem-terra" e na liberação de maior volume de recursos nos primeiros anos do governo Lula. Quanto à diminuição dos montantes, dois fatores merecem destaque: a evolução do cultivo de cana-deaçúcar e o recebimento dos incentivos de outras políticas públicas como, por exemplo, o programa estadual de microbacias hidrográficas.

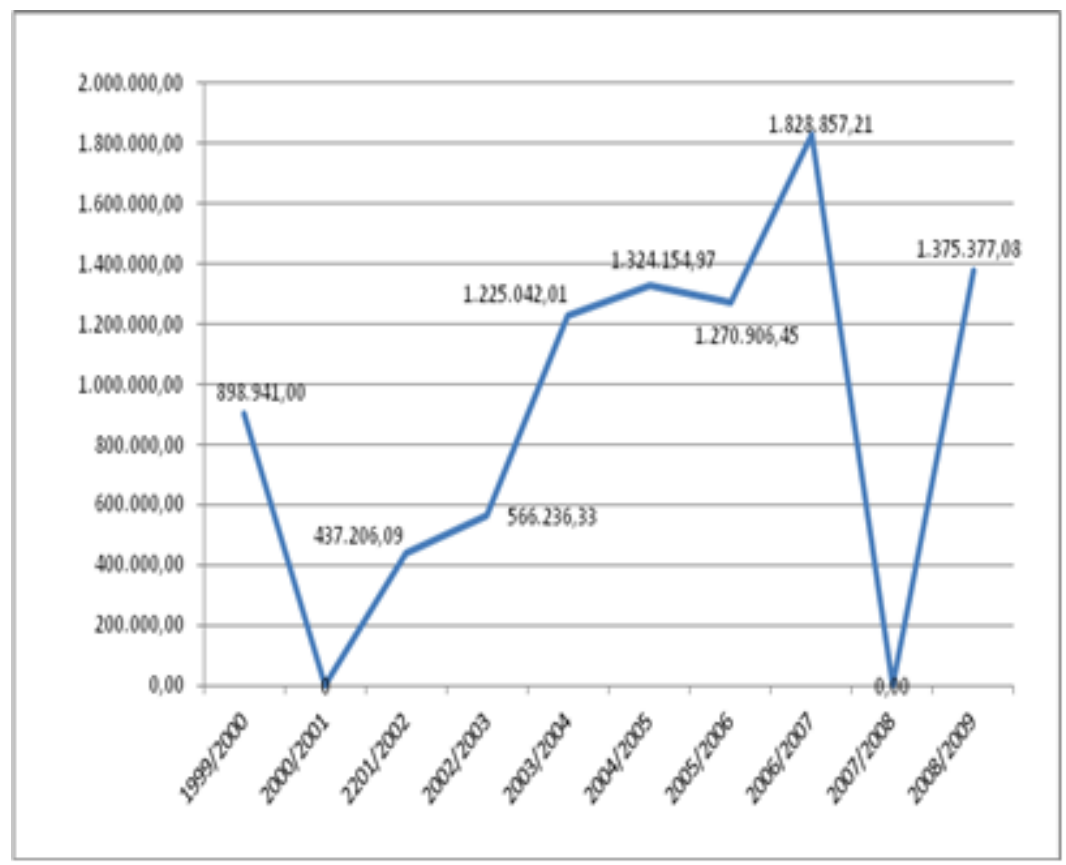

Figura 3. Evolução dos incentivos PRONAF no município de Presidente Bernardes/SP - 1999/2009 (R\$). Fonte: www.mda.gov.br/saf - $1^{0}$ sem 2010. 


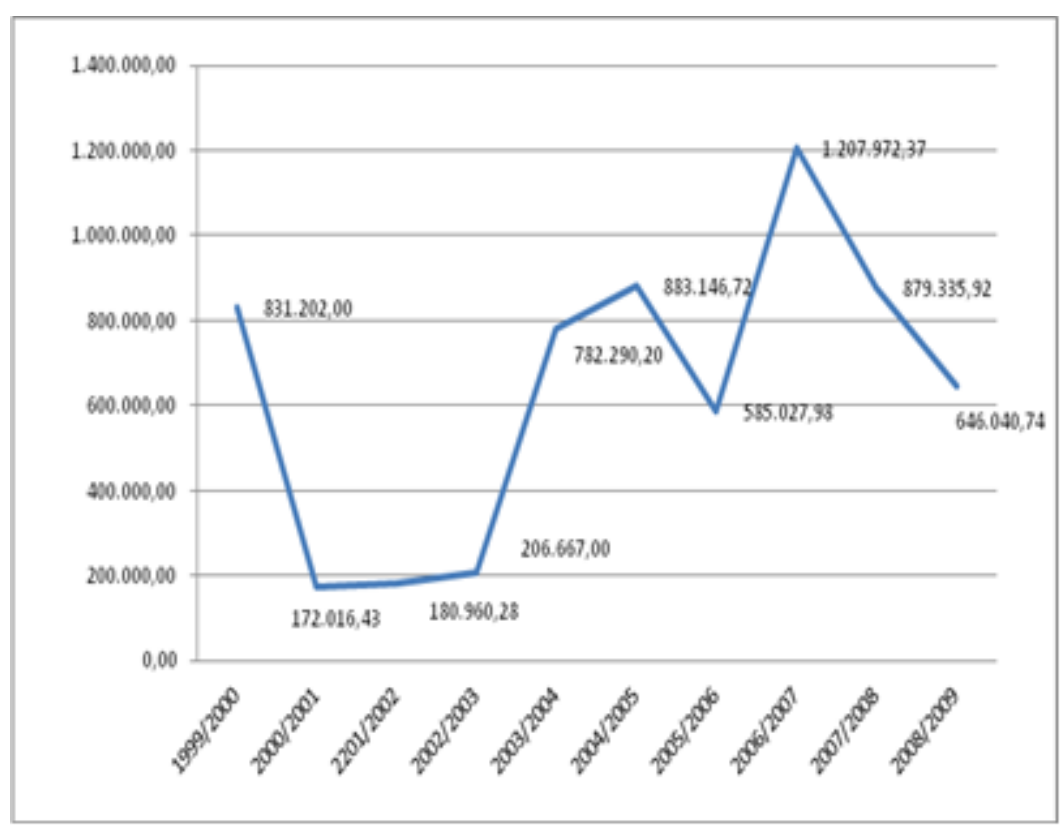

Figura 4. Evolução dos incentivos PRONAF no município de Martinópolis/SP - 1999/2009 (R\$). Fonte: www.mda.gov.br/saf - $1^{0}$ sem 2010.

Em Álvares Machado, os recursos aumentaram a partir dos anos agrícolas de 2002/03 e decresceram entre 2006/2007 e 2008/099 (figura 5). Em Caiabu e Santo Expedito os montantes foram os menores, mesmo porque no primeiro só houve interesse nos anos agrícolas de 2002/03 e 2005/06 e no segundo em 2003/04 (figuras 6 e 7). Em Indiana, o incremento se deu a partir de 2001/2002, seguindo até 2006/07, consoante ao aumento do efetivo de bovinos mistos, destinados à produção de leite (figura 8). Além disso, foram efetuados investimentos no cultivo de seringueira, na produção de ovos, na criação de suínos e no cultivo de $\operatorname{uvas}^{10}$.

\footnotetext{
${ }^{9}$ Segundo dados IEA (2010) houve incremento nas produções de leite e olerícolas, durante o período.

${ }^{10}$ Os Relatos dos produtores da Associação de Produtores do Bairro Sete Copas, corroboram com os dados do IEA (2010). Desde 2003, notifica-se a ascensão da cultura da seringueira no município. O crescimento do efetivo de galinhas poedeiras ocorreu de 2001 a 2007 o número de suínos para abate cresceu a partir do ano agrícola 2003/04. A produção de uva ganhou destaque em 2000, crescendo em 2005 (www.ciagri.iea.sp.gov.br).
} 


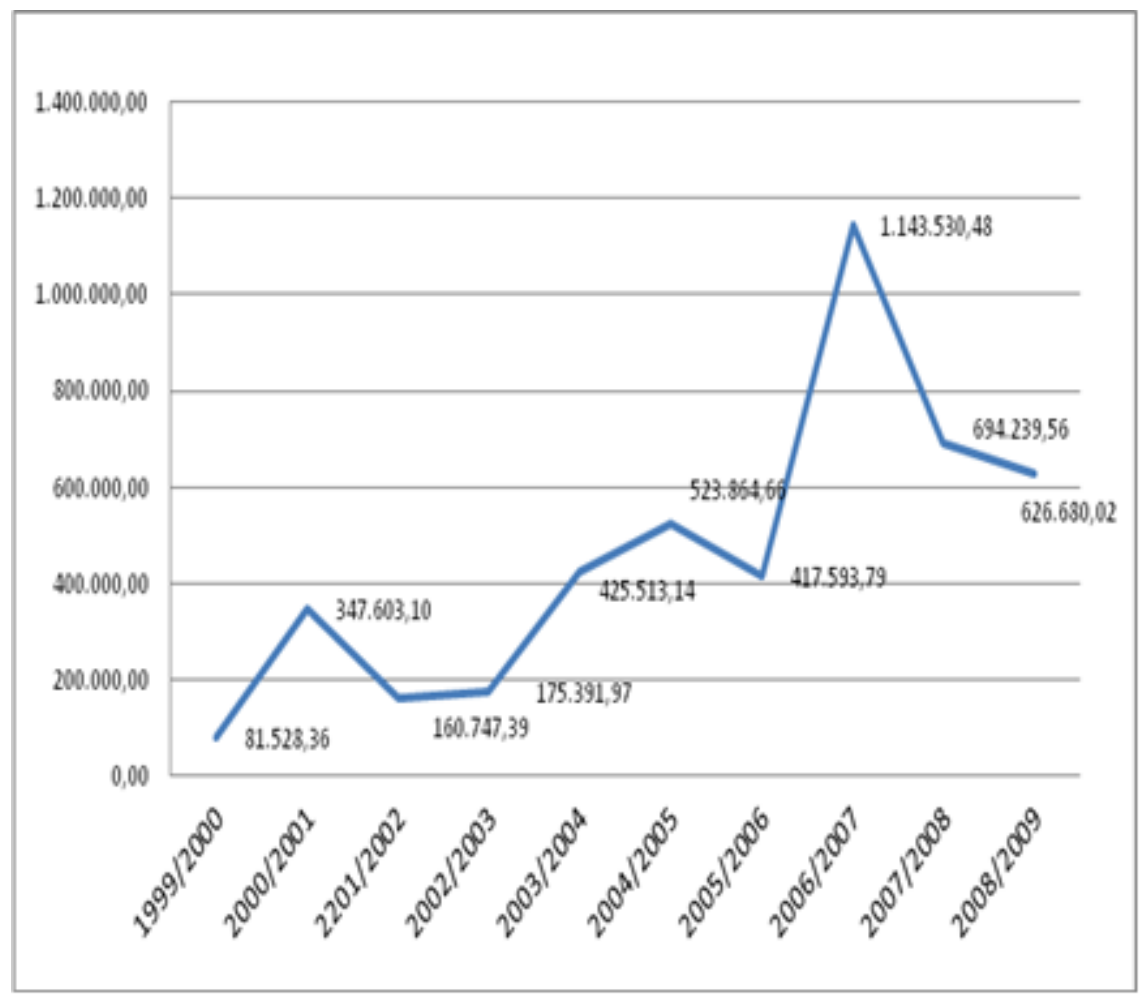

Figura 5. Evolução dos incentivos PRONAF no município de Álvares Machado/SP - 1999/2009 (R\$). Fonte: www.mda.gov.br/saf - $1^{0}$ sem 2010.

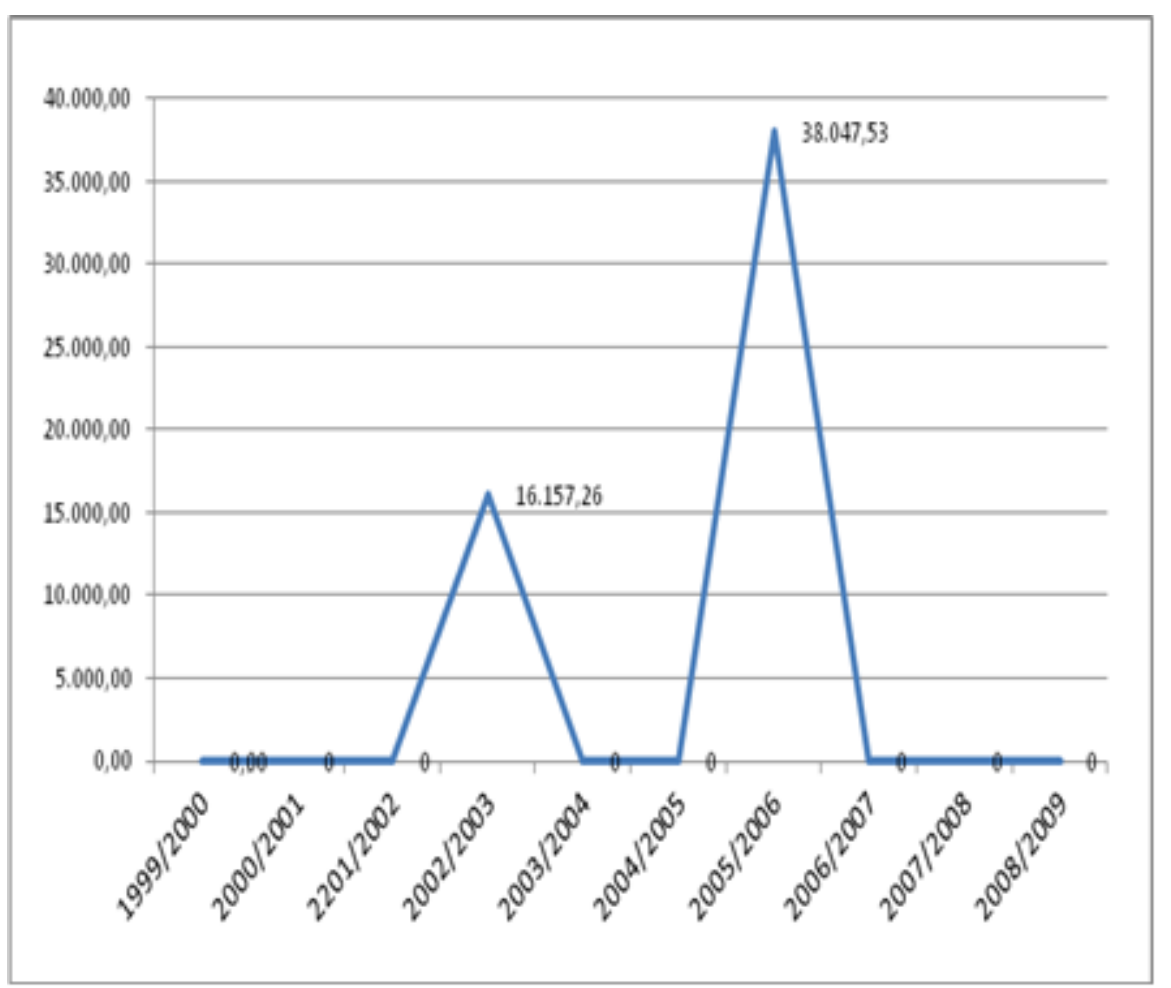

Figura 6. Evolução dos incentivos PRONAF no município de Caiabu/SP - 1999/2009 (R\$).

Fonte: www.mda.gov.br/saf - $1^{0}$ sem 2010. 


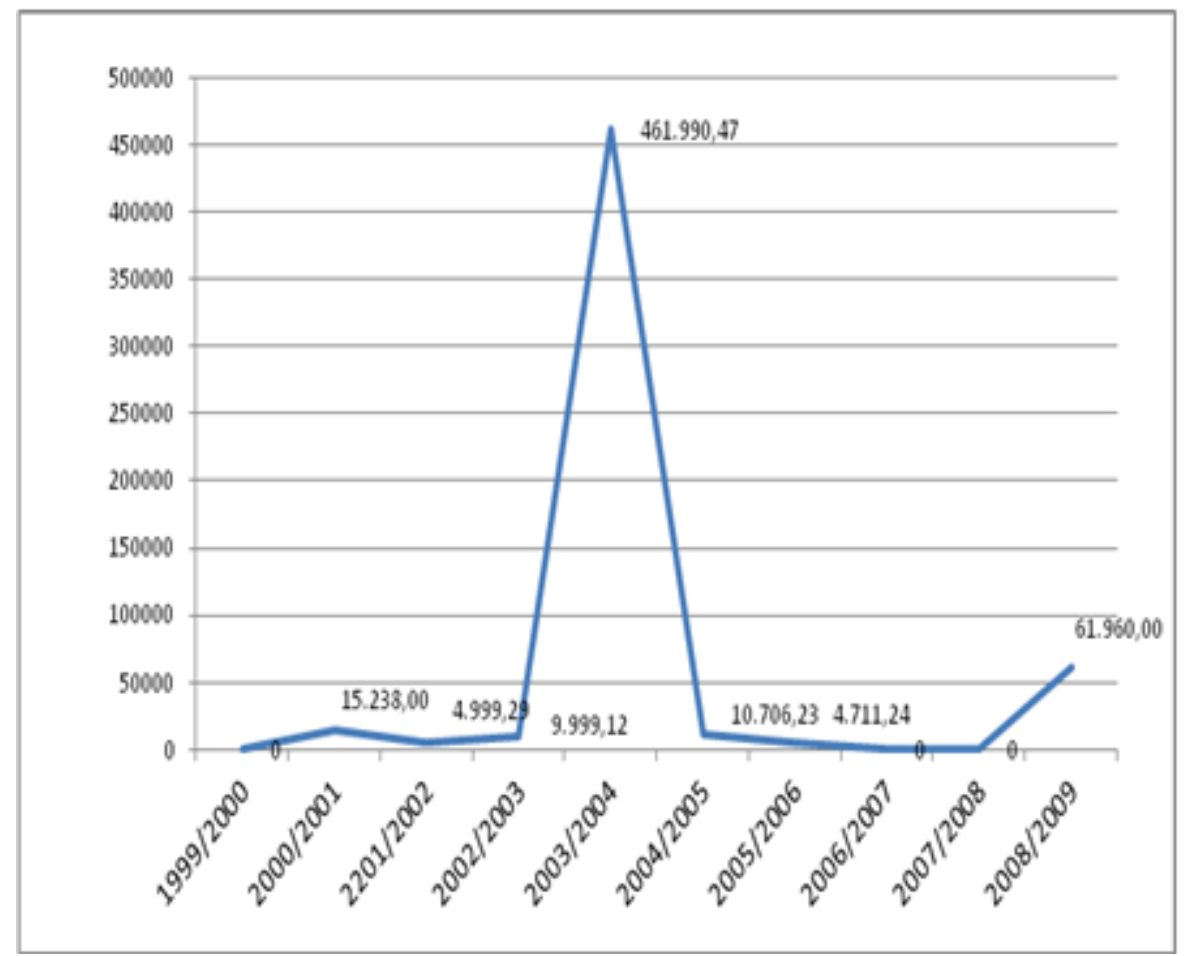

Figura 7. Evolução dos incentivos PRONAF no município de Santo Expedito/SP - 1999/2009 (R\$).

Fonte: www.mda.gov.br/saf - $1^{0}$ sem 2010.

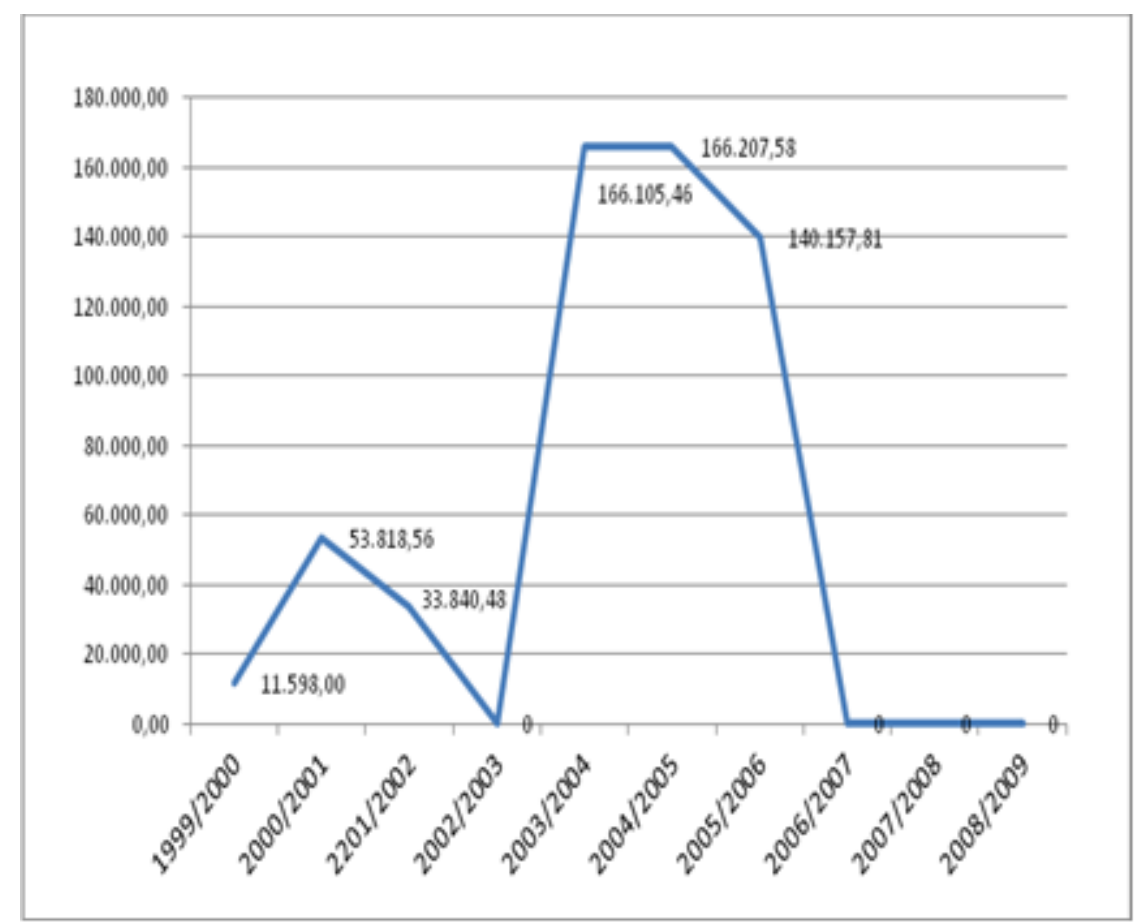

Figura 8. Evolução dos incentivos PRONAF no município de Indiana/SP - 19992009 (R\$).

Fonte: www.mda.gov.br/saf - $1^{0}$ sem 2010.

Em Alfredo Marcondes, houve significativa expansão do montante de recursos do PRONAF a partir de 2003/04, com pico no ano agrícola de 2007/08 (Figura 9). Já em Emilianópolis, os produtores não 
recorreram ao programa nos anos agrícolas 2001/02 e 2008/09, contudo, houve expansão na quantidade de recursos entre 2002/03 e 2006/07 (Figura 10).

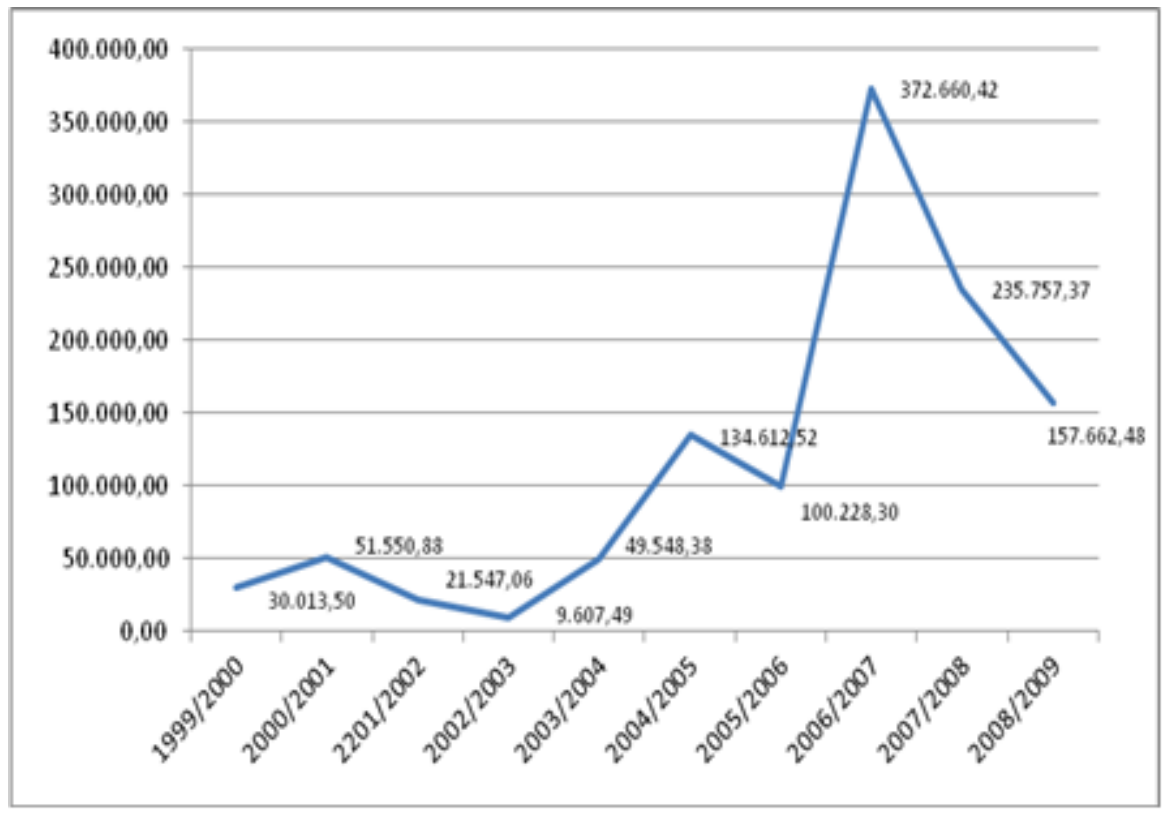

Figura 9. Evolução dos incentivos PRONAF no município de Alfredo Marcondes/SP - 1999/2009. Fonte: www.mda.gov.br/saf - $1^{0}$ sem 2010.

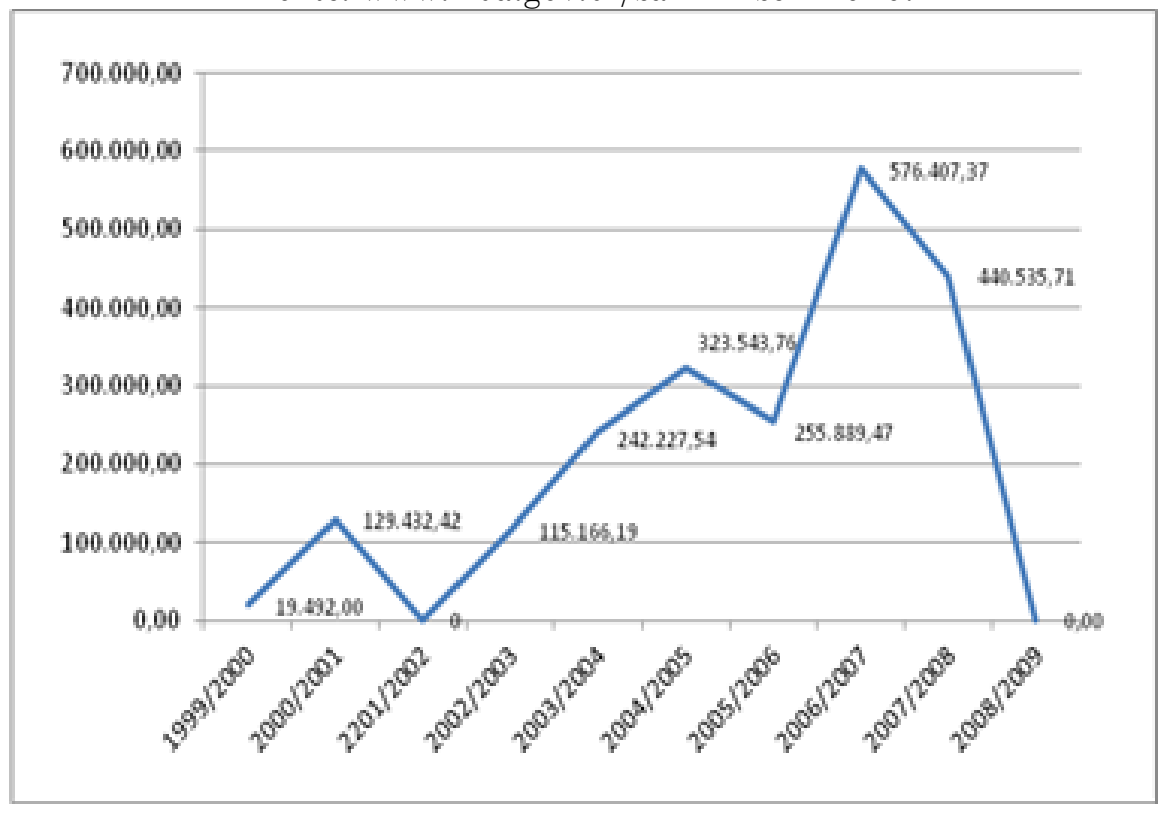

Figura 10. Evolução dos incentivos PRONAF no município de Emilianópolis/SP - 1999/2009 (R\$). Fonte: www.mda.gov.br/saf - $1^{0}$ sem 2010.

Apesar do aumento do número de contratos e dos recursos nos primeiros anos do século XXI, no EDR de Presidente Prudente a expansão ocorreu no governo Lula, pós 2002/03, com oscilação negativa somente no ano agrícola de 2007/08 (Figura 11). 
Em termos de número de contrato, verifica-se que os municípios de Presidente Bernardes e Martinópolis se destacaram com 1.642 e 1.105, respectivamente. Já Caiabu e Santo Expedito solicitaram apenas 43 e 47, respectivamente, durante dez anos. Embora os recursos do PRONAF se concentrassem em Presidente Bernardes, Martinópolis e Álvares Machado, comparando-se os montantes de recursos com o número de contratos nos dez anos (Tabela 1), constatou-se que a média de recursos - por produtor - foi maior em Alfredo Marcondes, com $\mathrm{R} \$ 6.433,44$ per capita ${ }^{11}$, depois em Álvares Machado, com $\mathrm{R} \$$ 5.665,71, seguido de Martinópolis, com $\mathrm{R} \$$ 5.378,00. Em Emilianópolis, a média foi de $\mathrm{R} \$ 5.079,43$ per capita e em Presidente Bernardes de $\mathrm{R} \$ 4.301,24$.

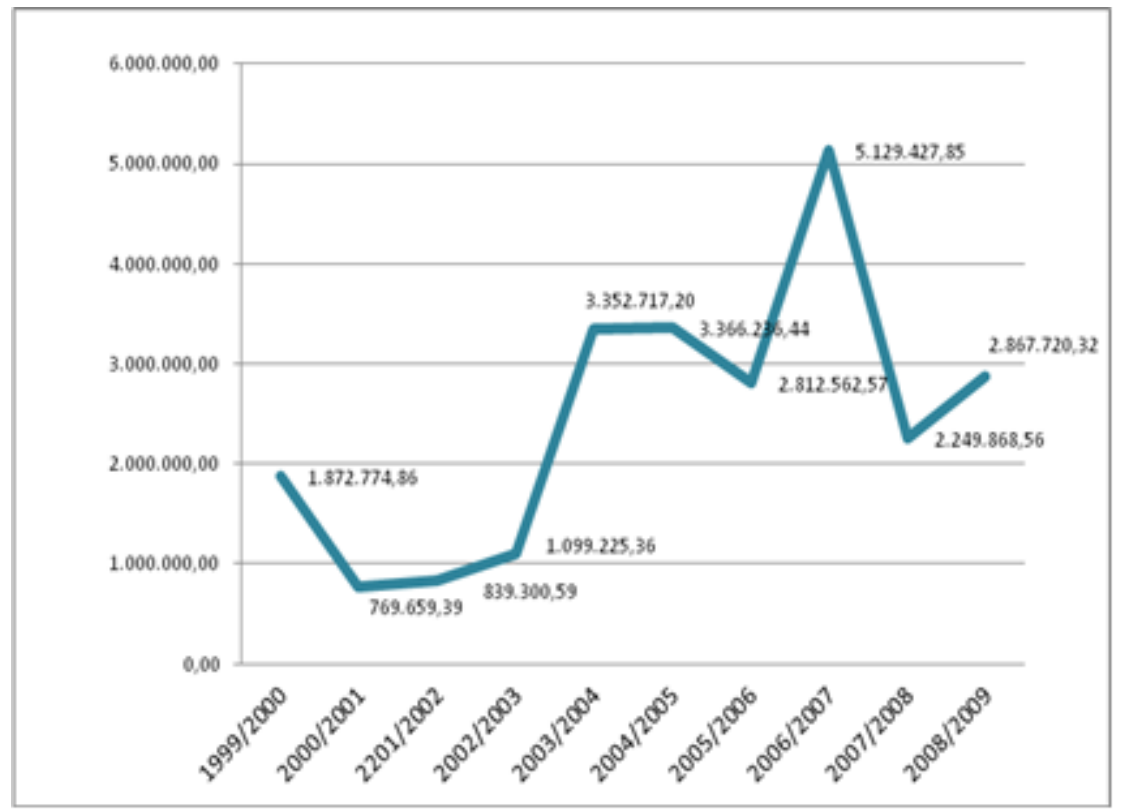

Figura 11. Montantes dos Recursos PRONAF destinados aos oito municípios estudados no EDR de Presidente Prudente - anos agrícolas 1999/2000 a 2008/2009 (R\$).

Fonte: www.mda.gov.br/saf, anos agrícolas 1999/00 - 2008/09.

\begin{tabular}{|c|c|c|c|c|c|c|c|c|c|}
\hline \multirow{2}{*}{$\begin{array}{c}\text { Ano } \\
\text { agrícola }\end{array}$} & \multicolumn{8}{|c|}{ Número de contratos por município } & \multirow{2}{*}{$\begin{array}{l}\text { Total } \\
\text { geral }\end{array}$} \\
\hline & $\begin{array}{c}\text { Alfredo } \\
\text { Marcondes }\end{array}$ & $\begin{array}{c}\text { Álvares } \\
\text { Machado }\end{array}$ & Caiabu & Emilianópolis & Indiana & Martinópolis & $\begin{array}{c}\text { Pres. } \\
\text { Bernardes }\end{array}$ & $\begin{array}{c}\text { Santo } \\
\text { Expedito }\end{array}$ & \\
\hline $1999 / 2000$ & 7 & 20 & 0 & 4 & 4 & 109 & 187 & 0 & 331 \\
\hline $2000 / 2001$ & 12 & 85 & 0 & 37 & 13 & 47 & 0 & 4 & 198 \\
\hline $2201 / 2002$ & 6 & 41 & 0 & 0 & 9 & 55 & 160 & 1 & 272 \\
\hline $2002 / 2003$ & 3 & 39 & 4 & 32 & 0 & 70 & 104 & 2 & 254 \\
\hline $2003 / 2004$ & 10 & 83 & 0 & 47 & 25 & 138 & 249 & 32 & 584 \\
\hline $2004 / 2005$ & 18 & 94 & 0 & 53 & 32 & 156 & 277 & 2 & 632 \\
\hline $2005 / 2006$ & 13 & 76 & 39 & 36 & 29 & 121 & 240 & 1 & 555 \\
\hline $2006 / 2007$ & 42 & 141 & 0 & 52 & 0 & 179 & 237 & 0 & 651 \\
\hline
\end{tabular}

${ }^{11}$ As médias per capita foram calculadas a partir da equação do montante em recursos dividido por número de contratos/ano, e retirada à média no período dos dez anos da série histórica PRONAF (MDA/SAF, 1999/2000 a 2008/2009). 


\begin{tabular}{|c|c|c|c|c|c|c|c|c|c|}
\hline $2007 / 2008$ & 25 & 100 & 0 & 47 & 0 & 136 & 0 & 5 & 313 \\
\hline $2008 / 2009$ & 15 & 71 & 0 & 0 & 0 & 94 & 188 & 0 & 368 \\
\hline Total & 151 & 750 & 43 & 308 & 112 & 1.105 & 1.642 & 47 & 4.158 \\
\hline
\end{tabular}

Tabela 1. Número de contratos do PRONAF nos municípios pesquisados no EDR de Presidente Prudente: série histórica dos anos agrícolas de 1999/2000 a 2008/2009.

Fonte: www.mda.gov.br/saf, anos agrícolas 1999/00 - 2008/09.

Nos anos agrícolas de 2004/05 e 2006/07 foi efetuado maior número de contratos, sendo 632 e 651 , respectivamente. Os anos agrícolas de menor adesão foram 2000/01 e 2002/03, com 198 e 254 contratos, respectivamente. Contudo, a quantidade de recursos pode não ser simétrica ao número de contratos, porque depende da linha de crédito e do valor financiado. A partir de 2003, com a mudança no projeto político nacional e a intensificação de investimentos na área social, houve grande incentivo para a utilização de crédito do PRONAF, com aumento no número de contratos, até o ano agrícola de 2007/08. Os dados do trabalho de campo mostraram que, em 2010, 20\% dos produtores entrevistados contraíram empréstimos do PRONAF.

\section{A produção familiar e os diferentes tipos de produtores rurais no EDR de Presidente Prudente/SP}

Com base na literatura sobre o $\mathrm{PRONAF}^{12}$ é possível perceber que a agricultura familiar desempenha papel mais importante nos municípios menos populosos. No entanto, buscou-se evidenciar essa categoria em municípios com predominância dos extratos de área que variam de 10 a 20, 20 a 50, e de 50 a 100 hectares.

Os aspectos mais relevantes da agricultura familiar na região são: a) a manutenção do modo de vida rural; b) a obtenção de renda em serviços urbanos; e, c) o recebimento de benefícios de prestação continuada, especialmente as aposentadorias, em razão da elevada média de idade da população residente no meio rural. Assim, as entrevistas realizadas nos referidos municípios focalizaram quatro eixos de análise: a) relações de trabalho e renda; b) produção e comercialização; c) infraestrutura rural;

\footnotetext{
12 Abramovay e Veiga (1999), R. Hespanhol (2000), Kageyama (2003), Schneider (2003; 2009), Schneider e Tartaruga (2005), Rodomsky (2006), Favareto (2007; 2009) e Bonnal e Maluf (2009).
} 
d) manejo dos recursos naturais. A classificação foi feita com base nas exigências regulatórias, técnicas e jurídicas quanto à definição de agricultura familiar e à normatização do PRONAF.

Os produtores rurais pesquisados foram classificados em três categorias, agrupando-os segundo as rendas, pessoas envolvidas no trabalho rural, ou não, tipo de produção agropecuária, infraestrutura das propriedades (quadro 1).

\begin{tabular}{|c|c|c|c|c|}
\hline Grupo/ Tipo & $\% / n^{0}$ & área (ha) & Características & Propriedade - Recursos - infraestrutura \\
\hline $\begin{array}{c}\text { Grupo I } \\
\text { Agricultores } \\
\text { familiares }\end{array}$ & $\begin{array}{l}62,5 \\
(50)\end{array}$ & $\begin{array}{c}10-20 \\
\quad \text { e } \\
20-50\end{array}$ & $\begin{array}{l}\text { a. Trabalho: } \\
\text { - A cargo da maioria dos membros da família; } \\
\text { - Mulher: intercalando gerenciamento do lar e } \\
\text { participação na administração da propriedade; } \\
\text { b. Renda: } \\
\text { - produção agropecuária } \\
\text { - pluriativa: } 74 \% \text { ( } 37 \text { produtores) - um ou dois } \\
\text { membros com ocupação urbana; } 12 \% \text { (6) } \\
\text { contam com as aposentadorias } \\
\text { e. Propriedade: multifuncional; policultora. } \\
\text { d. Produção: } \\
\text { - lavouras (milho, feijão, melancia, mandioca); } \\
\text { - pecuária; horticultura; } \\
\text { - criação: suíno, galinha caipira e outras aves } \\
\text { - peixe e pequenos animais } \\
\text { e. Meio ambiente: } \\
\text { - APP (onde havia mata nativa e onde houve } \\
\text { ação do PEMBH): } 84 \% \text { (42 produtores) } \\
\text { - reserva legal averbada: não regularizada na } \\
\text { maioria das propriedades. }\end{array}$ & $\begin{array}{l}\text { - Maquinários (trator, plantadeira, carreta } \\
\text { agrícola; triturador/moedor de ração; } \\
\text { distribuidor de calcário; pulverizador; } \\
\text { - Implementos: em algumas propriedades onde } \\
\text { se produz leite há tanque de } \\
\text { expansão/resfriamento; ordenha mecânica } \\
\text { (geralmente de uso coletivo com os produtores } \\
\text { vizinhos); } \\
\text { - tecnologia: computador; telefonia rural (fixa } \\
\text { ou celular); } \\
\text { - Infraestrutura: mais de uma casa } \\
\text { (alvenaria); uma ou mais represas } \\
\text { (barragem); tulha ou paiol (armazém); } \\
\text { reservatório de água (caixa); bomba } \\
\text { d'água; poço artesiano; fossas asséptica ou } \\
\text { comum; energia elétrica; cerca elétrica; } \\
\text { - assistência técnica: Casa da Agricultura ou } \\
\text { própria. }\end{array}$ \\
\hline $\begin{array}{c}\text { Grupo II } \\
\text { Agricultores } \\
\text { familiares } \\
\text { capitalizados } \\
\text { (empresa) }\end{array}$ & $\begin{array}{c}13,75 \\
(11)\end{array}$ & $50-100$ & $\begin{array}{l}\text { a. Trabalho: } \\
\text { - A cargo de alguns membros da família, } \\
\text { geralmente com auxílio de um ou dois } \\
\text { empregados ou diaristas (quando há excesso de } \\
\text { serviço) } \\
\text { - Mulher: gerenciamento do lar; } \\
\text { b. Renda: } \\
\text { - Uma renda principal; } \\
\text { - Rendas extras durante épocas do ano ou } \\
\text { ano/agrícola (de acordo com período de safras) } \\
\text { e. Propriedade: policultora (menos diversificada) } \\
\text { d. Produção: } \\
\text { - Pecuária (cria e leite); } \\
\text { - Suínos; } \\
\text { - Lavouras (milho, feijão, melancia, mandioca): } \\
\text { exceções. } \\
\text { - Granja; } \\
\text { e. Meio ambiente: } \\
\text { - Reconstituição da vegetação em APPs (onde } \\
\text { houve ação do PEMBH): cinco produtores }\end{array}$ & $\begin{array}{l}\text { - Maquinários: trator, plantadeira, carreta } \\
\text { agrícola, caminhão; triturador/moedor de } \\
\text { ração; calcareadeira; pulverizador; } \\
\text { colheitadeira } \\
\text { - Implementos: tanque de } \\
\text { expansão/resfriamento; ordenhadeira } \\
\text { mecânica (uso individual); instalações de } \\
\text { alvenaria para ordenha (mecanizada). } \\
\text { tecnologia: computador; telefonia rural (fixa } \\
\text { ou celular); } \\
\text { - Infraestrutura: mais de uma casa } \\
\text { (alvenaria); uma ou mais represas } \\
\text { (barragem); tulha ou paiol (armazém); } \\
\text { reservatório de água (caixa); bomba } \\
\text { d'água; poço artesiano; fossas asséptica ou } \\
\text { comum; energia elétrica; cerca elétrica; } \\
\text { Assistência técnica: Casa da Agricultura e } \\
\text { particular }\end{array}$ \\
\hline
\end{tabular}




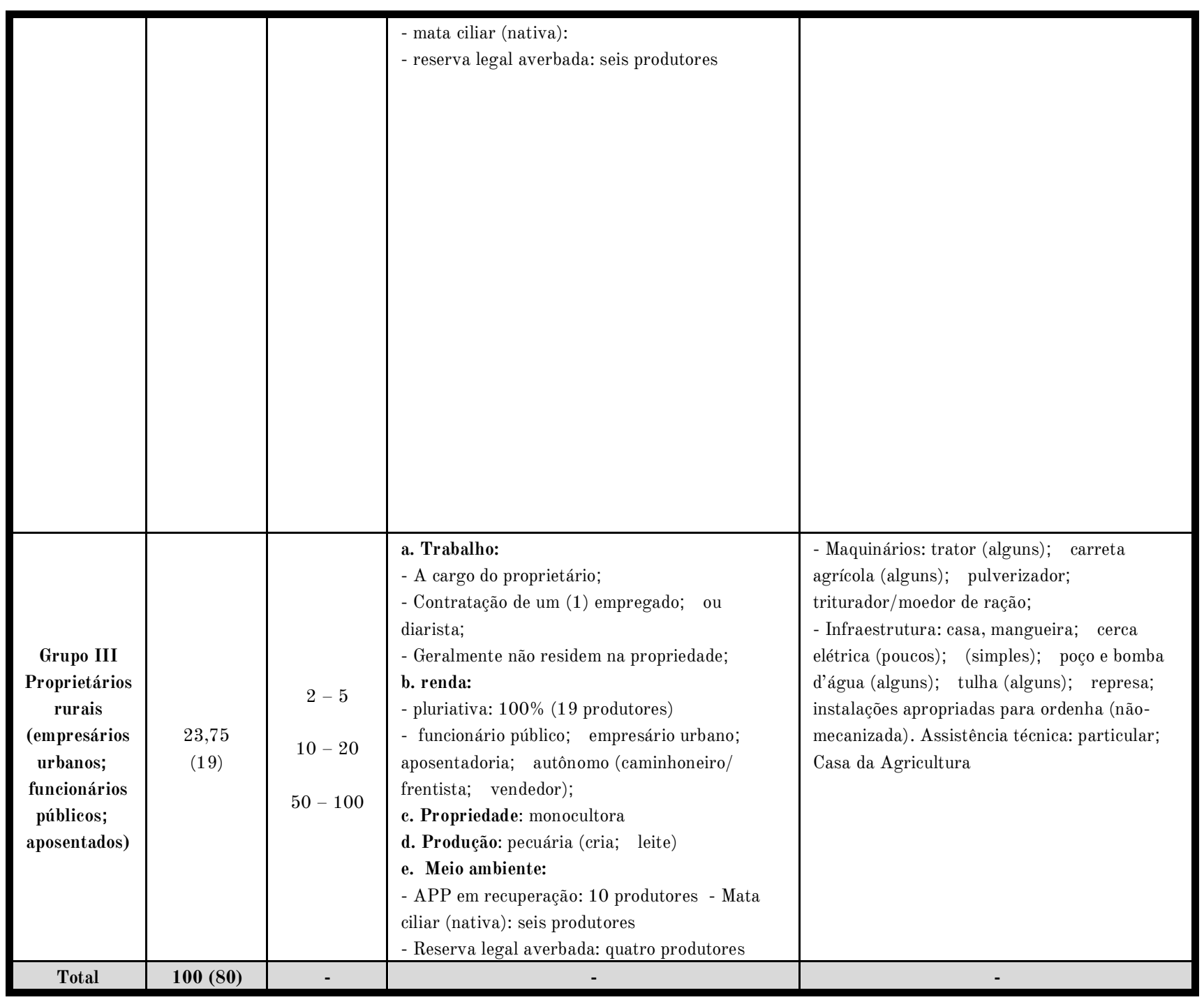

Quadro 1. Tipos de produtores rurais dos municípios estudados no EDR de Presidente Prudente/SP.

Fonte: trabalho de campo, 2010.

Nessas propriedades, geralmente residem os pais e parte da família. Nelas são desenvolvidas atividades diversificadas, tais como: a criação de gado bovino, suínos e galinhas caipiras; a exploração de lavouras, principalmente milho e feijão; a produção de leite destinada ao mercado regional e ao consumo próprio; e, a horticultura (específica no Grupo I) para o consumo interno e comercialização local.

No Grupo III as propriedades variam de 2 a 5 hectares, 20 a 50 e, eventualmente, de 50 a 100 hectares. Embora as propriedades sejam familiares, os serviços, reparos e atividades produtivas são executados por um dos membros da família (em tempo parcial) e um empregado (quando há). As rendas provêm da exploração de um produto, diferentemente do que ocorre com os produtores rurais 
do Grupo I, esses, intercalam rendas agrícolas e não-agrícolas, contudo estão ligados à criação de gado e produção de leite.

Constatou-se, por intermédio da pesquisa, que a propriedade rural não é espaço exclusivo da produção agropecuária. Além de ser base produtiva, é local de residência e refúgio familiar, espaço de lazer e descanso, local de preservação dos recursos naturais e do patrimônio que se valoriza no mercado imobiliário. Segundo Norder (2006), atualmente, a gestão da pequena propriedade fica a cargo de alguns membros da família, sendo a pluriatividade importante para a reprodução desta categoria de produtores.

Para o referido autor,

\begin{abstract}
isto nos leva a refletir sobre o significado da noção de patrimônio na agricultura familiar do ponto de vista do consumo produtivo e, consequentemente, do seu papel para o desenvolvimento de atividades não-agrícolas e para a dinamização de economias locais e regionais, notadamente nos município com reduzida proximidade e interação com a dinâmica econômica dos grandes centros regionais e nacionais. (NORDER, 2004, p. 78).
\end{abstract}

Todavia, o gerenciamento do patrimônio com recursos múltiplos tem como finalidade promover a interação entre o meio rural e os demais setores produtivos locais. Não é necessariamente o tamanho da propriedade ou a sua posse que determina a qualidade da reprodução social dos agricultores familiares. A boa gestão dos recursos naturais disponíveis e seu aproveitamento adequado são de fundamental importância para a reprodução social dos agricultores familiares.

\title{
A agricultura familiar e a utilização do PRONAF em municípios pesquisados no EDR de Presidente Prudente/SP
}

Os oito municípios pesquisados no EDR de Presidente Prudente possuem grande número de estabelecimentos agropecuários classificados como de agricultura familiar (Figura 12). Desde os anos 1920 e 1930 a ocupação dessas áreas se deu com forte participação desta categoria de produtores. Muito do que se produziu na agropecuária ao longo de quase um século foi fruto do trabalho familiar, na condição de proprietários, colonos, meeiros e arrendatários. 


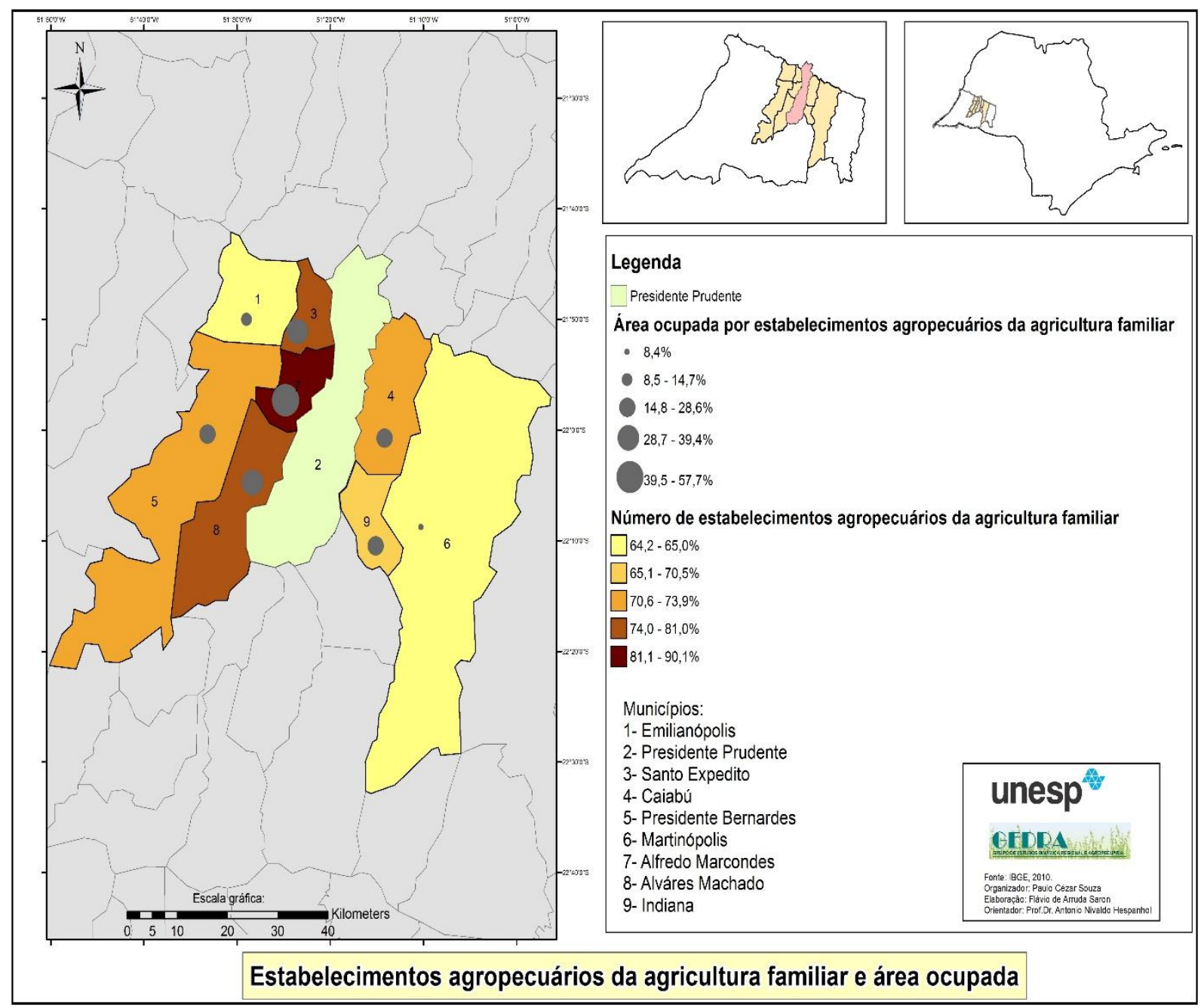

Figura 12. Estabelecimentos agropecuários da agricultura familiar e área ocupada nos oito municípios pesquisados no EDR de Presidente Prudente/SP (2010) - (\%).

Fonte: os autores.

Considerando-se a relação território e porcentagem de área ocupada pela agricultura familiar, exceto Martinópolis, os outros sete municípios possuem mais de 14,8\% de sua área ocupada por este tipo de estabelecimento, com destaque para Alfredo Marcondes com cerca de 40\% do território ocupado pela agricultura familiar.

Tendo em vista a área ocupada por estabelecimentos da agricultura familiar, como observado no figura 12, Álvares Machado e Santo Expedito, possuem cerca de 25\% e Alfredo Marcondes possui 39,6 \%. Em Presidente Bernardes, Caiabu e Indiana, a área ocupada pela agricultura familiar está em torno de 15\%, em Emilianópolis é cerca de 10\% e em Martinópolis menos de 8,4\% (BRASIL, 2010). 
De acordo com o Levantamento de Unidades de Produção Agropecuária (LUPA, CATI, 1995/6 e 2007/8), a maior concentração fundiária foi evidenciada em Martinópolis, enquanto em Alfredo Marcondes, Álvares Machado e Santo Expedito, a concentração é menor. Contrapondo-se as áreas ocupadas pela agricultura familiar ao número de estabelecimentos, verificou-se o predomínio de agricultores familiares nos municípios menores. Em Martinópolis, a agricultura familiar ocupa menos de $10 \%$ da área e o número de estabelecimentos é menor. Essa divergência decorreu da extensão territorial e das especificidades geográfica internas do município ${ }^{13}$ (Figura 13).

Apesar de se entender que grande parte dos recursos destinou-se a municípios que possuem assentamentos rurais, a operacionalidade do programa se mostrou efetiva no EDR, como pode ser observado na distribuição espacial do número de contratos e do montante de recursos aplicados entre 1999 a 2009 (Figura 13). Em linhas gerais, verificou-se que esta política pública tem sido mais aceita e requisitada pelos assentados do que pelos demais agricultores familiares.

No caso dos municípios menores, verificou-se a efetivação do "PRONAF infraestrutura e serviços municipais" no período inicial, o que levou muitos produtores a não optar pelos créditos individuais, devido a possibilidade de acesso aos recursos por intermédio das associações de produtores rurais e das casas da agricultura locais. Neste caso, segundo R. Hespanhol (2000) as associações de produtores rurais de Alfredo Marcondes, Álvares Machado, Presidente Bernardes e Emilianópolis, usufruíram dessa linha de incentivos, principalmente na segunda metade da década de 1990.

\footnotetext{
${ }^{13}$ Martinópolis possui dois tipos distintos de ocupação e utilização do solo. A parte sul, que corresponde a $60 \%$ do território, é ocupada por latifúndios com propriedades acima de 1.000 hectares. Na parte norte (40\% da área), predominam as pequenas e médias propriedades, caracterizadas por estabelecimentos da agricultura familiar (SOUZA, 2004).
} 


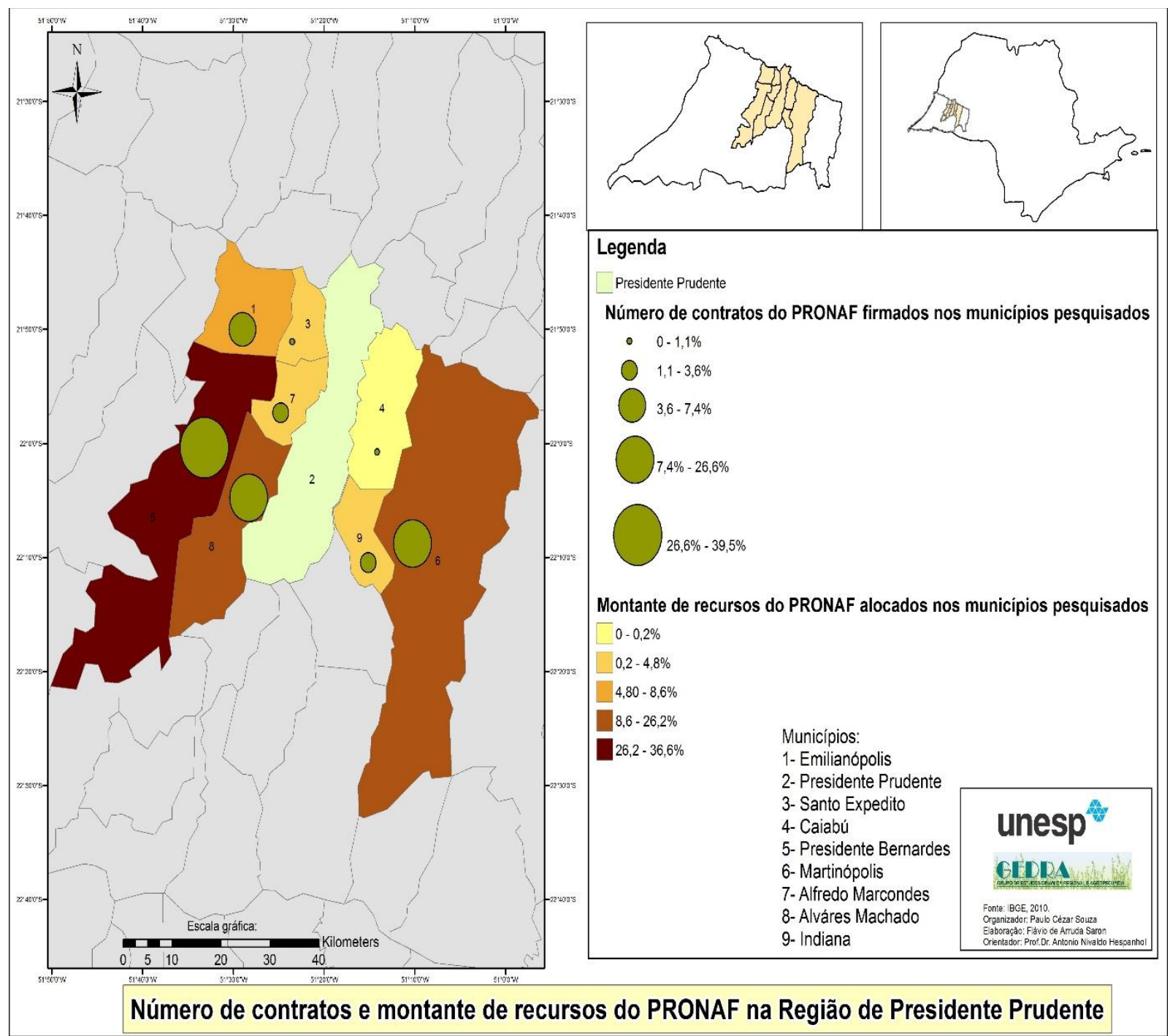

Figura 13. Porcentagem de contratos e montantes dos recursos do PRONAF nos oito municípios pesquisados no EDR de Presidente Prudente/SP em relação ao total do EDR.

Fonte: os autores.

\section{As repercussões do PRONAF junto aos produtores rurais dos municípios pesquisados no EDR de Presidente Prudente/SP}

O PRONAF foi e é bem aceito pelos produtores rurais pesquisados. Até mesmo quem nunca solicitou crédito entende a importância dessa política pública para os agricultores familiares. Em linhas gerais, os problemas se concentram na resistência em contrair financiamento e na burocracia bancária. A operacionalidade e as exigências do programa são bem aceitas. As baixas taxas de juros e as facilidades de pagamento são atrativos para os interessados em investir em máquinas, implementos e melhorar a infraestrutura das propriedades, bem como para custear a produção, como pode ser identificado no quadro 2. 


\begin{tabular}{|c|c|c|l|l|}
\hline \multicolumn{5}{|c|}{ Utilização do Crédito PRONAF (1996 - 210) } \\
\hline Situação & $\mathbf{N}^{\mathbf{0}}$ Produtores & \% Produtores & \multicolumn{1}{c|}{ Relatos (gerais) } \\
\hline Sim & 45 & $\begin{array}{l}\text { a) Utilizar crédito PRONAF somente em caso de extrema necessidade, para custeio; } \\
\text { b) No caso de investimentos, somente em caso de mudar a base produtiva ou intensificar } \\
\text { as técnicas } \\
\text { c) juros baixos e prazo estendido para pagamento (adimplência) } \\
\text { b) burocracia; tempo para organizar documentação e liberação dos recursos }\end{array}$ \\
\hline Não & 35 & $\begin{array}{l}\text { a) produzir com recursos próprios e ter o mínimo de compromisso com bancos; } \\
\text { b) burocracia bancária; } \\
\text { c) dificuldade em arrumar }\end{array}$ \\
\hline Total & 80 & 100 &
\end{tabular}

Quadro 2. Utilização do crédito e relatos sobre o PRONAF por parte dos produtores rurais dos municípios pesquisados no EDR de Presidente Prudente (1996 - 2010).

Fonte: trabalho de campo: produtores rurais e secretários municipais de agropecuária.

Para compreender as repercussões e os impactos causados pelo PRONAF na região foram investigados produtores que utilizaram crédito do programa; as opiniões; os tipos de incentivos; onde utilizaram os recursos e quais os problemas enfrentados para o acesso aos recursos. Dentre os 80 entrevistados, $45(56,25 \%)$ relataram ter usado crédito do PRONAF. 35 (43,75\%), mesmo havendo interesse, nunca utilizaram (Quadro 2).

Dentre os $56,25 \%$ dos produtores que recorreram ao programa, apenas $16,25 \%$ tiveram pequenos problemas com documentação bancária, outros 28,75\% relataram não haver empecilho ou dificuldade; $11,25 \%$ não lembravam dos valores solicitados. Nenhum dos produtores se referiu a inadimplência ou dificuldade de pagamento; $16 \%$ não se enquadraram em nenhuma das linhas de crédito, porque a maior parte das rendas não provem da produção agropecuária ou por não residirem no município. Dentre os mesmos, 62,2\% utilizaram a modalidade custeio e 37,8\% à modalidade investimento (Quadro 2). Nenhum dos pesquisados esboçou descontentamento com o PRONAF, quitaram os empréstimos e conseguiram descontos previstos nas normas. Entre 1996 e 2010, 56\% dos produtores rurais pesquisados relataram que acessaram crédito do PRONAF apenas uma única vez, 18\% contraíram duas vezes e $27 \%$ três vezes ou mais. Os que se utilizaram uma ou duas vezes são produtores de milho, feijão e amendoim. Os pecuaristas concentraram investimentos na compra de animais de cria, como pode ser observado no quadro 3. 


\begin{tabular}{|c|c|c|}
\hline $\begin{array}{l}\text { PRONAF/ } \\
\text { \% adesão }\end{array}$ & & \\
\hline $\begin{array}{c}\text { Custeio } \\
62,2 \%\end{array}$ & $\begin{array}{l}\text { Produção agrícola em geral: } \\
\text { - Aquisição de sementes de milho, feijão e amendoim. } \\
\text { - Aquisição de mudas de seringueira e eucalipto. } \\
\text { - Aquisição de mudas cítricas (laranja, murcote, poncã e } \\
\text { limão). } \\
\text { - Mudas para parreiras de uva. } \\
\text { - Mudas de banana. } \\
\text { - Correção do solo: calcário e nitrato. } \\
\text { - Aquisição de animais para produção e reprodução: vacas } \\
\text { leiteiras, novilhos (bezerros e garrotes), suínos e galinha } \\
\text { poedeira. }\end{array}$ & $\begin{array}{l}\text { - Alfredo Marcondes, Indiana, Emilianópolis e Pres. } \\
\text { Bernardes. } \\
\text { - Indiana e Caiabu. } \\
\text { - Indiana, Santo Expedito e Caiabu. } \\
\text { - Indiana e Presidente Bernardes. } \\
\text { - Pres. Bernardes, Martinópolis, Santo Expedito, Álvares } \\
\text { Machado e Alfredo Marcondes. } \\
\text { - Caiabu, Indiana, Álvares Machado e Emilianópolis. }\end{array}$ \\
\hline $\begin{array}{c}\text { Investimento } \\
37,8 \%\end{array}$ & $\begin{array}{l}\text { Infraestrutura da propriedade: } \\
\text { - Implementos agrícolas de baixo custo. } \\
\text { - Construção de instalações para ordenha mecânica, } \\
\text { mangueira e chiqueiros. } \\
\text { - Construção de cercas (divisão de pastos e da propriedade) } \\
\text { - Terraço e reforma de pastagens. } \\
\text { - Reformas e adequação de barracão de frangos } \\
\text { - Energia elétrica (instalação e ampliação) } \\
\text { - Instalação de poços e bombas d'água. }\end{array}$ & $\begin{array}{l}\text { - Alfredo Marcondes, Álvares Machado, Pres. Bernardes e } \\
\text { Indiana. } \\
\text { - Álvares Machado, Santo Expedito, Martinópolis, Pres. } \\
\text { Bernardes e Alfredo Marcondes. } \\
\text { - Alfredo Marcondes, Álvares Machado, Pres. Bernardes. } \\
\text { - Álvares Machado, Alfredo Marcondes, Pres. Bernardes e } \\
\text { Martinópolis, } \\
\text { - Santo. Expedito e Alfredo Marcondes. } \\
\text { - Pres. Bernardes, Alfredo Marcondes e Caiabu. } \\
\text { - Martinópolis, Álvares Machado, Alfredo Marcondes e } \\
\text { Santo Expedito. }\end{array}$ \\
\hline
\end{tabular}

Quadro 3. Adesão às linhas do PRONAF pelos produtores rurais pesquisados no EDR de Presidente Prudente no período de 1996 a 2010 e principais aplicações dos recursos.

Fonte: Pesquisa de campo, 2010.

De acordo com os relatos dos produtores rurais pesquisados, os recursos do PRONAF foram utilizados na produção de leite, suínos, frutas (limão, poncã, uva e banana) e de milho. Os produtores que recorreram mais de uma vez ao PRONAF afirmaram total segurança em usar os empréstimos para aumentar a produção agropecuária, melhorar a infraestrutura da propriedade e fazer o manejo adequado dos recursos naturais, principalmente do solo (Quadro 3).

O PRONAF também favoreceu a diversificação produtiva em muitas propriedades, sobretudo em Alfredo Marcondes e Indiana. Em Álvares Machado, houve maior interesse pela pecuária leiteira e, em Martinópolis, Presidente Bernardes e Santo Expedito, os recursos foram direcionados, principalmente, a pecuária mista.

Os setores da propriedade ou tipo de produção onde foram empregados os recursos do PRONAF, entre 1996 a 2010 são diversos. Contatou-se que $25 \%$ dos produtores pesquisados buscaram recursos para aplicar na produção leiteira, 12,5\% em lavouras temporárias e 12,5\% em infraestrutura geral da 
propriedade. Os produtores investiram também na compra de animais para produção e reprodução, sendo que $6,25 \%$, na pecuária de cria e corte, e 5\%, na compra de aves e suínos. Apenas 2,5\% investiram em culturas permanentes, como seringueira e eucalipto (Figura 14).

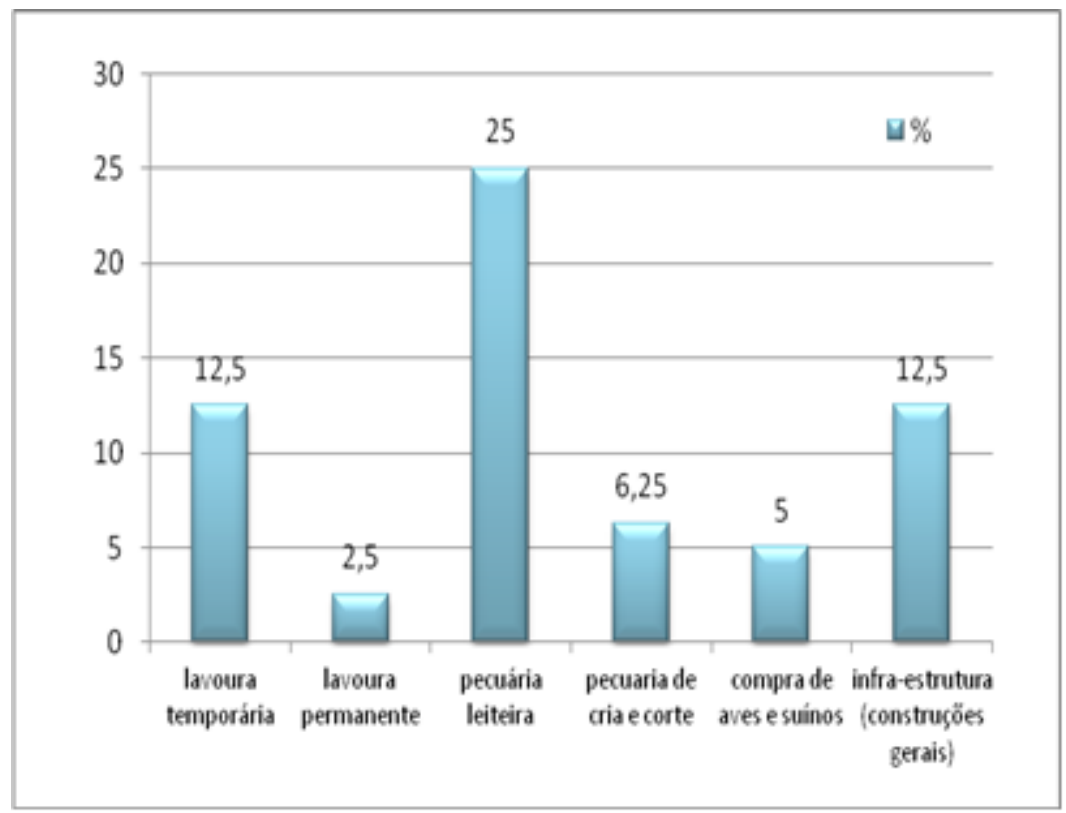

Figura 14. Setor da propriedade e tipo de produção agropecuária em que os produtores dos municípios do EDR de Presidente Prudente utilizaram os recursos.

Fonte: trabalho de campo, 2010.

Algumas localidades recorreram mais ao PRONAF "infraestrutura e serviços municipais", nos primeiros anos do programa. Essa linha de crédito foi utilizada na compra de insumos agrícolas sobretudo adubos e calcário -, aquisição de máquinas, tratores e implementos agropecuários, por parte das associações de produtores rurais ${ }^{14}$.

As associações de produtores rurais que fizeram maior aquisição de máquinas e equipamentos foram as de Alfredo Marcondes (AFRAM) e Álvares Machado, lembrando-se das associações de produtores rurais de Emilianópolis e Presidente Bernardes que também receberam incentivos do PRONAF

\footnotetext{
${ }^{14}$ De acordo com R. Hespanhol (2006), “[...] entre os vinte e um (21) municípios componentes do EDR de Presidente Prudente, constatou-se a existência de associações de produtores em vinte (20) destes". Os municípios que se destacavam, em 2006, pelo número de associações eram Presidente Bernardes e Álvares Machado, com oito e três associações, respectivamente.
} 
"infraestrutura e serviços municipais" e foram apoiadas pelas casas de agricultura locais, com efetiva participação dos técnicos e da prefeitura municipal.

Dentre os oito municípios pesquisados, os que mais agregaram incentivos foram Alfredo Marcondes, Álvares Machado, Emilianópolis e Presidente Bernardes, através das associações de produtores rurais, caracterizadas por agregar produtores familiares e de pequeno porte (R. HESPANHOL, 2006). Nestes municípios foram igualmente oferecidas linhas de crédito coletivas ${ }^{15}$ no período 1999/2000. As associações de produtores rurais se organizaram na compra de implementos, insumos e equipamentos para manutenção e aumento da produção agropecuária local.

Segundo relatos dos representantes das instituições, foram adquiridos insumos e calcário, tratores, colheitadeiras (pequena), tombadores, plantadeiras, pulverizadores (de chão e costal), carretas agrícolas, subsoladores, distribuidores de calcário, redes de energia elétrica, cercas elétricas; tanques de expansão e ordenhas mecânicas; foram pagas horas de trabalho/trator/máquina para construção de terraços e bacias de contenção de água nas estradas rurais.

$\mathrm{Na}$ verdade, no que se refere às condições de produção, o acesso ao crédito é de fundamental importância para manutenção da infraestrutura e inovação tecnológica, acesso ao mercado e no aumento da produção e da produtividade, visto as facilidades oferecidas pelo programa. Contudo, os produtores defenderam a implantação de outras ações como o fortalecimento do associativismo e novas parcerias com órgãos públicos (quadro 4).

Por fim, no quadro 4 encontram-se resumidas as considerações dos produtores rurais sobre o PRONAF e as expectativas em relação ao programa, contemplando as opiniões conjuntas sobre o significado do PRONAF até 2010 e as expectativas no que concerne à produção individual e às associações de produtores.

\footnotetext{
15 O PRONAF “infraestrutura e serviços municipais” foi uma linha de crédito concedida pelo Governo Federal, no período de 1997/2000 com possibilidade de financiamentos "[...] com recursos não-reembolsáveis em parceria com os governos municipais, tendo como objetivo a implementação, a ampliação, a racionalização da infra-estrutura pública e de serviços de apoio ao desenvolvimento da agricultura familiar" (R. HESPANHOL, 2006, p. 16).
} 


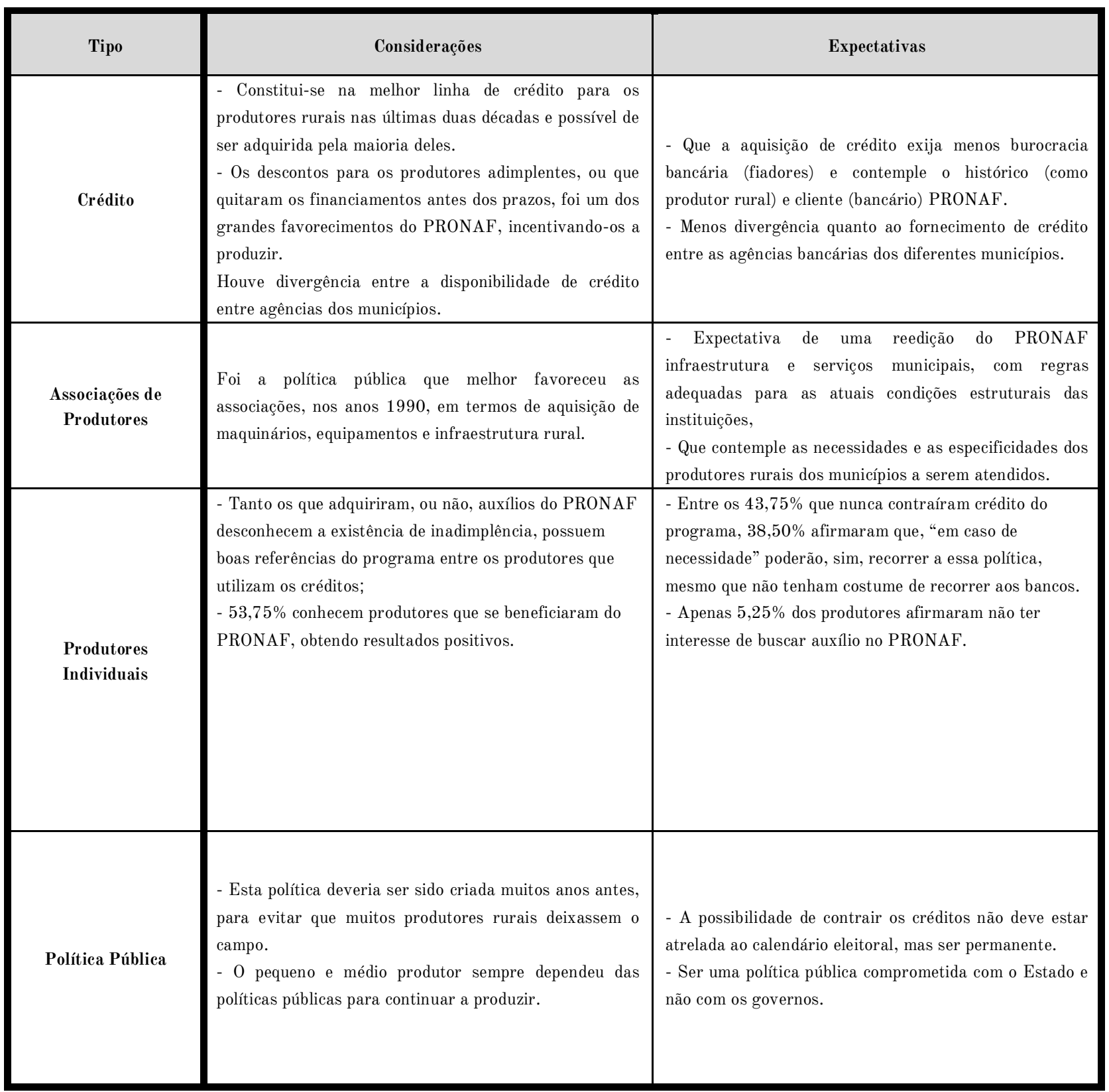

Quadro 4. Considerações e expectativas dos produtores pesquisados nos oito municípios estudados no EDR de Presidente Prudente em relação ao PRONAF.

Fonte: trabalho de campo: produtores rurais e secretários municipais de agropecuária.

Na verdade, constatou-se que o PRONAF se configurou na melhor linha de crédito ao alcance dos pequenos e médios produtores rurais no Brasil. Mesmo evidenciando-se alguns gargalos no período inicial, quando o acesso ao programa era mais restrito, o mesmo se consubstanciou como uma possibilidade efetiva de incentivo ao crédito a ser utilizado na manutenção da propriedade rural como fonte de renda e sustento familiar nas regiões pobres, e, amenizar a pobreza das famílias que vivem eminentemente do que produzem em suas propriedades rurais. De fato, constatou-se também baixa inadimplência junto nas linhas de crédito do programa, pouca burocracia e juros acessíveis, mesmo 
porque, segundo os produtores e associações reconhecem que as políticas públicas para pequenos e médios produtores rurais precisam estar na pauta dos programas de governo, de forma permanente.

\section{CONSIDERAÇÕES FINAIS}

A partir da Constituição de 1988, muitos programas passaram a ser implementados em parceria com os municípios, induzindo a participação social por meio das associações de produtores rurais. Ainda que seja inovador e existam muitos entraves, a gestão participativa é referência para se criar e implementar projetos e programas que objetivam promover o desenvolvimento econômico e social.

O PRONAF foi se constituindo ao longo do tempo num programa que permite distribuir recursos entre as regiões brasileiras, contemplando a diversidade produtiva existente no meio rural. Em linhas gerais, constata-se o avanço no reconhecimento da agricultura familiar, como importante política pública para as regiões rurais mais pobres, sendo que os aspectos positivos superaram os negativos.

No Oeste Paulista, especificamente nos municípios do EDR de Presidente Prudente, mesmo sabendose que o montante total aportado não atingiu a 25 milhões de reais, foi identificado pontos positivos, tais como: a) a manutenção da propriedade e a continuidade da produção agropecuária junto à parcela dos produtores que optaram em permanecer no meio rural; b) o crescimento das propriedades policultoras; c) a combinação de atividades agrícolas e não-agrícolas no meio rural; d) o estabelecimento de parcerias entre produtores, associações, poder público e setor privado, e; e) a possibilidades de se criar políticas públicas vinculadas a agricultura familiar, em outras instâncias de governo.

Mesmo com a procura pelos incentivos do PRONAF nos primeiros anos do programa, constatou-se que nos municípios estudados o montante de recursos foi baixo, em comparação com as condições oferecidas pelo "PRONAF infraestrutura e serviços municipais e as linhas individuais de crédito e de investimento". Nota-se que o perfil cultural do produtor rural nestas áreas, mesmo com a existência de associações, cooperativas e sindicatos, não se enquadra no modelo cooperativo e associativista, que os 
níveis de instrução formal e de empreendedorismo são baixos ou insuficientes para se adequarem rapidamente ao modelo produtivo de mercado. Todavia, mesmo com esses relativos problemas, as políticas públicas para o meio rural demonstraram-se eficaz no incentivo ao associativismo e ao empreendedorismo, mesmo porque, permanece a noção de patrimônio a preocupação com o manejo dos recursos naturais, dos quais foram fonte de sustento das famílias em tempos anteriores e, segundo os pequenos produtores rurais, podem continuar sendo fonte de sustento e agregação de valor para as futuras gerações.

Assim, fica evidente a importância do PRONAF como um programa inovador no âmbito das políticas públicas para o meio rural no Brasil e, particularmente nos municípios pouco dinâmicos e fortemente dependentes das atividades agropecuárias.

\section{REFERÊNCIAS}

ABRAMOVAY, Ricardo; VEIGA, Jose Eli da. Novas Instituições para o Desenvolvimento Rural: o caso do Programa Nacional da Agricultura Familiar (PRONAF). Brasília, abril, 1999. Texto para discussão 641, Convênio FIPE/IPEA $07 / 97$.

ANDRADE, Ilza, A. L. Conselhos de Desenvolvimento Rural: espaço adequado para se pensar o desenvolvimento local? In: SCHNEIDER, Sergio; SILVA, Marcel. K; MARQUES, Paulo E. M. (Org). Políticas públicas e participação social no Brasil. Porto Alegre: UFRGS Editora, 2004. p. 233-250.

BONNAL, Philipe e MALUF, Renato S. Políticas de desenvolvimento territorial e a multifuncionalidade da Agricultura Familiar no Brasil. In: COLÓQUIO INTERNACIONAL DE DESENVOLVIMENTO TERRITORIAL SUSTENTÁVEL, I., 2007. Florianópolis. NMD/UGSC, 2007.p. 1 - 26.

CAZELlA, Ademir Antonio. Base de Serviços Rurais Estratégicos à Promoção do Desenvolvimento Territorial no Brasil. Revista Raízes, Campina Grande, v. 28, n. 1 e 2, jan-dez/2009; v. 29, n. 1, 132 - 142. jan-jun/2010.

COORDENADORIA DE ASSISTÊNCIA TÉCNICA INTEGRAL (CATI). Dados Consolidados Regionais, 1995/96, 2007/08, Região Agrícola de Presidente Prudente. Levantamento Censitário das Unidades de Produção Agropecuária Estado de São Paulo (Lupa). Disponível na internet em: http://www.cati.sp.gov.br/projetolupa/dadosregionais.php. Acessado em jan/2010

FAVARETO, Arilson. Paradigmas do desenvolvimento rural em questão. São Paulo: Ilgu - Fapesp, 2007.

FAVARETO, Arilson. As tentativas de adoção da abordagem territorial do desenvolvimento rural - lições para uma nova geração de políticas públicas. Revista Raízes, Campina Grande, v. 28, n. 1 e 2, jan-dez/2009; v. 29, n. 1, p. 52 - 62. janjun/2010. 
GRAZIANO DA SILVA, José. A nova dinâmica da agricultura brasileira. Unicamp, Instituto de Economia-II. Campinas, 1998.

GUANZIROLI, C. E. PRONAF dez anos depois: resultados e perspectivas para o desenvolvimento rural. RER, Rio de Janeiro, v. 45. n.02, p. 301 - 328, abr./jun, 2007.

HESPANHOL, A. Nivaldo; HESPANHOL, Rosangela Ap. de M. Desenvolvimento rural e poder local: a situação dos CMDRs na região de Presidente Prudente. In SEMINÁRIO INTERNACIONAL - Desenvolvimento local na integração: Estratégias, Instituições e Políticas, I., 2004.Rio Claro. Anais(?)... Rio Claro: IGCE - Unesp, 2004.p. 1 - 16.

HESPANHOL, Rosangela Ap. Medeiros. Produção familiar: perspectivas de análise e inserção na Microrregião Geográfica de Presidente Prudente - SP. 2000. Tese (Doutorado em Geografia)- Universidade Estadual Paulista - Unesp "Julio de Mesquita Filho", Instituto de Geociências e Ciências Exatas (IGCE), Campus de Rio Claro - SP, 2000.

HESPANHOL, Rosângela A. M. Diagnóstico da Situação das Associações de Produtores na Região de Presidente Prudente - SP. CONGRESSO DA SOBER “Questões Agrárias, Educação no Campo e Desenvolvimento”, XLIV, 2006, Fortaleza. (CE): 2006. P. 1 - 11.

KAGEYAMA, A. Produtividade e renda na agricultura familiar: efeitos do PRONAF - crédito. Agric. São Paulo, v. 50, n.2, p. $1-13,2003$.

NAVARRO, Zander. A agricultura familiar no Brasil: entre a política e as transformações na vida econômica. In:

GASQUES, J. G; VIEIRA FILHO, J. E. R; NAVARRO, Zander (Org). Agricultura brasileira: desempenho, desafios e perspectivas. Brasília - DF, IPEA, Governo Federal, 2010. Disponível em:

http://www.alice.cnptia.embrapa.br/bitstream/doc/904333/1/AgriculturafamiliarnoBrasilcap.7.pdf. Acesso em: em jul. 2011.

GRAZIANO DA SILVA, José. 0 novo rural brasileiro. Campinas/SP:IE-UNICAMP, 1999.

NORDER, Luiz A. C. Mercantilização da Agricultura e desenvolvimento territorial. In: SCHNEIDER, Sergio (Org.). A diversidade da agricultura familiar. Porto Alegre, UFRGS Editora, 2006.p. 59-86.

PAULILO, Maria Ignêz S. Maricultura e território em Santa Catarina - Brasil. In: AUED, Bernadete W.; PAULILO, M. I. S. (Org.). Agricultura familiar. Florianópolis, Ed. Insular, 2004. p. 19-36.

RODOMSKY, Guilherme W. Reciprocidade, redes sociais e desenvolvimento rural. In: SCHNEIDER, Sergio (Org.). A diversidade da agricultura familiar. Porto Alegre, UFRGS Editora, 2006. p. 107-138.

SCHNEIDER, Sergio. A pluriatividade na agricultura familiar. 2.ed. Porto Alegre, UFRGS Editora, 2003.

SCHNEIDER, Sergio. A abordagem territorial do desenvolvimento rural e suas articulações externas. Dossiê, sociologias, Porto Alegre, ano. 6, n. 11, p. 88-125, jan./jun. 2004.

SCHNEIDER, Sergio; CAZELLA, A.A.; MATTEI, Lauro. Histórico, Caracterização e dinâmica recente do Pronaf Programa Nacional de Fortalecimento da Agricultura Familiar. In: SCHNEIDER, Sergio; SILVA, Marcel. K; MARQUES, Paulo E. M. (Org.). Políticas públicas e participação social no Brasil. Porto Alegre: UFRGS Editora, 2004. p. 21-54.

SCHNEIDER, S.; TARTARUGA, I. G. P. Território e abordagem territorial: das referências cognitivas aos apostes aplicados à análise dos processos sociais rurais. Revista Raízes, cidade? v. 23, n. 1 e 2, p. 101-116, jan./dez. 2006.

SILVA, Marcel. K; MARQUES, Paulo E. M. Democratização e políticas públicas de desenvolvimento. In: SCHNEIDER, Sergio; SILVA, Marcel. K; MARQUES, Paulo E. M. (Org.). Políticas públicas e participação social no Brasil. Porto Alegre: UFRGS Editora, 2004. p. 9-20. 
SOUSA, J. M. P.; VALENTE JR, A. S. Análise das Liberações dos Recursos do PRONAF - descentralização das aplicações do crédito rural? In: ONGRESSO DA SOCIEDADE BRASILEIRA DE ECONOMIA E SOCIOLOGIA RURAL (SOBER), XLIV,2006 Fortaleza. SOBER, 2006. p. 1-19.

SOUZA, P. C e HESPANHOL, A. N. Bairros Rurais e Resistência. A Formação das Comunidades Rurais no Oeste Paulista. Campo-Território: revista de Geografia Agrária, v. 5, n. 10, p. 168-193, ago. 2010. Disponível em http://www.seer.ufu.br/index.php/campoterritorio. Acessado em agosto de 2010.

VEIGA, José Eli. O Brasil rural ainda não encontrou seu eixo de desenvolvimento. Estudos Avançados: Dossiê Desenvolvimento Rural, São Paulo, v.5 n. 43, IEA/USP, p.101-120, set./dez. 2001.

WANDERLEY, Maria de N. Baudel. Olhares sobre o rural brasileiro. Revista Raízes, Campina Grande, v. 23, n 1 e 2, p.8298, jan./dez. 2004. 